IZA DP No. 7990

Donating Time to Charity: Not Working for Nothing

Yu Aoki

February 2014

Forschungsinstitut zur Zukunft der Arbeit Institute for the Study of Labor 


\title{
Donating Time to Charity: Not Working for Nothing
}

\author{
Yu Aoki \\ University of Aberdeen \\ and IZA
}

\section{Discussion Paper No. 7990 \\ February 2014}

\author{
IZA \\ P.O. Box 7240 \\ 53072 Bonn \\ Germany \\ Phone: +49-228-3894-0 \\ Fax: +49-228-3894-180 \\ E-mail: iza@iza.org
}

Any opinions expressed here are those of the author(s) and not those of IZA. Research published in this series may include views on policy, but the institute itself takes no institutional policy positions. The IZA research network is committed to the IZA Guiding Principles of Research Integrity.

The Institute for the Study of Labor (IZA) in Bonn is a local and virtual international research center and a place of communication between science, politics and business. IZA is an independent nonprofit organization supported by Deutsche Post Foundation. The center is associated with the University of Bonn and offers a stimulating research environment through its international network, workshops and conferences, data service, project support, research visits and doctoral program. IZA engages in (i) original and internationally competitive research in all fields of labor economics, (ii) development of policy concepts, and (iii) dissemination of research results and concepts to the interested public.

IZA Discussion Papers often represent preliminary work and are circulated to encourage discussion. Citation of such a paper should account for its provisional character. A revised version may be available directly from the author. 
IZA Discussion Paper No. 7990

February 2014

\section{ABSTRACT}

\section{Donating Time to Charity: Not Working for Nothing ${ }^{*}$}

This paper explores the causal effect of volunteer work providing daily assistance to the elderly on elderly mortality. To identify the causal effect, I exploit the earthquake that occurred in midwestern Japan in 1995 as a natural experiment inducing exogenous variation in the level of volunteering. The municipalities hit by the earthquake experienced a sharp increase in the level of volunteering. Based on a comparison of mortality between the municipalities with no or little loss of life due to the earthquake, that experienced the sharp increase in the level of volunteering, and the nearby municipalities that were not hit by the earthquake, I find that volunteering significantly reduced elderly mortality. Close attention is paid to ensure that the results are not driven by the direct effects of the earthquake.

JEL Classification: $\quad$ I10, J14

Keywords: volunteer labor, charity, mortality

Corresponding author:

Yu Aoki

Department of Economics

Business School

University of Aberdeen

Dunbar Street

Old Aberdeen, AB24 3QY

United Kingdom

E-mail: y.aoki@abdn.ac.uk

\footnotetext{
* Financial support from the University of Warwick is gratefully acknowledged. I am very grateful to Fabian Waldinger for his constant support and guidance. The detailed comments on earlier drafts by Wiji Arulampalam and Eric Strobl that greatly helped improve this paper are also acknowledged. I would like to thank Sascha O. Becker, Sonia Bhalotra, Hidehiko Ichimura, Victor Lavy, Rocco Macchiavello, Anandi Mani, Robin Naylor, Katherine Swartz, Heidi Williams, Christopher Woodruff and the participants of the EEA/ESEM Annual Congress in Malaga, the IZA/CEPR European Summer Symposium in Labor Economics in Ammersee, the Annual Conference of the Scottish Economic Society in Perth, the SIRE Young Researchers Forum at the University of Edinburgh, the ESPE Annual Conference in Aarhus, the Economics of Disasters Conference at the University of Brunel, and seminars at the University of Aberdeen and the University of Warwick for discussions that improved this paper. All remaining errors are my responsibility.
} 


\section{Introduction}

Millions of people across the world work for free. For example, more than a quarter of citizens in Japan and the United States and more than 40 percent of citizens in the United Kingdom participate in volunteer work. ${ }^{1}$ Spending leisure time volunteering may not only generate utility to volunteers but may also yield benefits to society. Despite the scale and popularity of volunteer activity, however, formal research on its potential benefits is scarce. Among the various types of volunteer work, this study focuses on the effect of volunteer work providing daily assistance to the elderly on elderly mortality.

Clarifying the impact of volunteer work is important for several reasons. Firstly, longer and healthier lives are an obvious source of an individual's happiness. Thus, the potentially significant impact endorses the importance of volunteer activity. Secondly, given global population aging, health care expenditures are likely to rise further. Clarifying the contribution of volunteering to longevity and better health is therefore important for the overall maintenance of society. Finally, studying donations of money to charity, List and Lucking-Reiley (2002) suggest that individuals donate more money if they believe that their contribution helps achieve the goal of the charity. To the extent that the same mechanism holds for donations of time to charity, revealing the potentially significant impacts of volunteering may prompt individuals to engage in this activity.

A major challenge to identify the causal effect of volunteering on mortality is the endogeneity of volunteering. There may be more volunteers in municipalities with a large number of people with a high risk of mortality such as the elderly. It is thus hard to conclude if the level of volunteering affects mortality or vice versa. Equally, unobserved heterogeneity across municipalities that affects both mortality and the level of volunteering (e.g., the quality of local health care services) may bias estimates of the effect of volunteering.

To identify the causal effect of volunteering on mortality, I use variation in volunteering caused by the Kobe earthquake, which occurred in the midwestern part of Japan in 1995. During 1,500 years of recorded history, Kobe had never been struck by major earthquakes prior to 1995 (United Nations Center for Regional Development, 1995). Thus, the earthquake was arguably unanticipated, providing exogenous variation in volunteering. The level of volunteering considerably increased in municipalities hit by the earthquake, while other municipalities did not experience such a sharp increase in volunteering. Based on a comparison of mortality between the municipalities with no or little loss of life due to the earthquake, that experienced the sharp increase in the level of volunteering, and the nearby municipalities that were not hit by the earthquake, my results indicate that volunteering significantly reduced the mortality among people in their 70s and

\footnotetext{
${ }^{1}$ Japanese, UK and US data are from the Survey on Time Use and Leisure Activities 2011, the Citizenship Survey 2010/2011 and the Current Population Survey 2011, respectively. The figures are percentages of respondents who engaged in volunteer work at least once in the past 12 months.
} 
80s or older. Evaluated at the mean, the estimate implies that approximately one life of a person aged 80 or older (out of 125 persons) was saved in a given year when the number of volunteers increased by 100 (out of 1,389 persons). Although the nature of the data does not allow me to determine if the reduction is driven by a reduction in the mortality of volunteers or care recipients, supporting evidence suggests that the reduction is likely to have occurred among care recipients. Furthermore, supplementary regressions to infer the mechanisms through which volunteering reduces mortality suggest that volunteering is likely to have reduced elderly morality by providing a quicker access to medical facilities and/or improving general health conditions of the elderly. Close attention is paid and a series of robustness checks are conducted to establish that the results are not driven by some effects of the earthquake other than volunteering, such as changes in public resources and healthcare capacity as well as broader changes in general altruism and social cohesion that are plausibly correlated with volunteering.

To the best of my knowledge, this is the first paper to examine the causal effect of volunteering on its outcome with an arguably credible identification strategy. Surprisingly, the effects of volunteering, especially its effect on the recipients of volunteer service, have been overlooked despite its enormous potential effects given the scale and popularity of volunteer activity. Instead previous research on volunteering conducted by economists primarily focuses on determinants of the supply of volunteer labor, seeking to understand why people work for free (Day and Devlin, 1998; Duncan, 1999; Freeman, 1997; Menchik and Weisbrod, 1987). The studies most closely related to this topic are those on donations of money, as opposed to time, to charity that investigate people's motivations to donate and optimal ways of fund-raising (Andreoni, 1989, 1990; Benabou and Tirole, 2006; DellaVigna et al., 2012; Fong and Luttmer, 2009; Grossman, 2010; Landry et al., 2006; Shang and Croson, 2009; Vesterlund, 2003).

The outcomes of volunteer work have been analyzed by social scientists in other disciplines, such as gerontology, sociology, and psychology. Their primary focus is on its effect on the wellbeing and mental health of volunteers themselves such as happiness, life satisfaction, self-reported health and depression (Morrow-Howell et al., 2003; Musick and Wilson, 2003; Piliavin and Siegl, 2007; Thoits and Hewitt, 2001; Van Willigen, 2000; Young and Glasgow, 1998). Among these studies there are several papers particularly focusing on the effect of volunteer work on mortality (Harris and Thoresen, 2005; Musick et al., 1999; Oman et al., 1999; Shmotkin et al., 2003). More precisely, using the Cox proportional hazards model, these papers compute hazard ratios for mortality that indicate the relative risk of mortality compared to a reference group conditional on control variables and find lower mortality risk among volunteers relative to non-volunteers. An issue with these studies is that it is not clear if volunteering reduces the risk of death or if people with a low risk of mortality participate in volunteering from the outset.

There is, however, one paper that exploits a difference in timing to address the endogeneity 
of volunteering. Specifically, Luoh and Herzog (2002) estimate its effect on the mortality of volunteers and find that elderly Americans who engaged in volunteer work for 100 hours or more are less likely to die relative to those who volunteered for fewer than 100 hours. Their analytical strategy is to regress mortality status in period $t$ on volunteer participation status in period $t-1$ to identify the causal effect of volunteering on mortality, controlling for health status prior to participation in volunteer work (i.e., health status in period $t-2$ ). A potential issue with their approach is that estimates of the effect of volunteering are biased if time-invariant unobserved heterogeneity that affects the health status of an individual is also correlated with the volunteer participation status of the individual. ${ }^{2}$

The remainder of the paper proceeds as follows. Section 2 explains the earthquake and its effect on volunteering. Section 3 presents the econometric specification and discusses empirical problems and the identification strategy. Section 4 describes data on mortality, volunteering and earthquake damage to be analysed, while Section 5 discusses the main empirical findings and investigates the type of death that is affected by volunteer work to infer the mechanisms through which volunteering reduces mortality. A series of robustness checks and falsification exercises are conducted in Section 6. Particularly, careful attention is paid to ensure that the main results are not driven by changes in some factors other than volunteering in the wake of the earthquake, such as changes in public resources and broader changes in community solidarity and social capital. Finally, Section 7 discusses policy implications and concludes the paper.

\section{The Earthquake and Volunteer Work}

The Kobe earthquake, officially called the great Hanshin-Awaji earthquake, occurred on 17 January 1995 with its epicenter in Hyogo Prefecture. The square in Panel A of Figure 1 indicates the location of Hyogo Prefecture, while the cross in Panel B indicates the epicenter. The earthquake recorded a magnitude of 7.3 and the maximum possible intensity of 7 on the Japanese intensity scale in the southern part of Hyogo Prefecture. ${ }^{3}$ The earthquake caused the second largest loss of life in post-war Japan: 6,434 people were killed, 40,092 people were injured, and more than 300,000 people evacuated. More than 682,182 homes, factories, and shops were destroyed or burnt down and infrastructure such as water, electricity, gas supplies and phone lines were seriously disrupted.

\footnotetext{
${ }^{2}$ Another potential issue is that Luoh and Herzog (2002) group those who did not volunteer and those who volunteered fewer than 100 hours into the same category and use them as a reference group. In other words, the reference group also contains those who participated in volunteer work. Thus, it is hard to interpret their estimates. In addition, the previous literature uses different cut-off values for measures of volunteering, e.g., the cut-off value of 40 hours in Musick et al. (1999), while the value is 100 hours in Luoh and Herzog (2002). It is therefore not clear how robust their results are to different cut-off values.

${ }^{3}$ The seismic intensity of 7 is assigned to an earthquake strong enough to alter a landform or cause a landslide.
} 


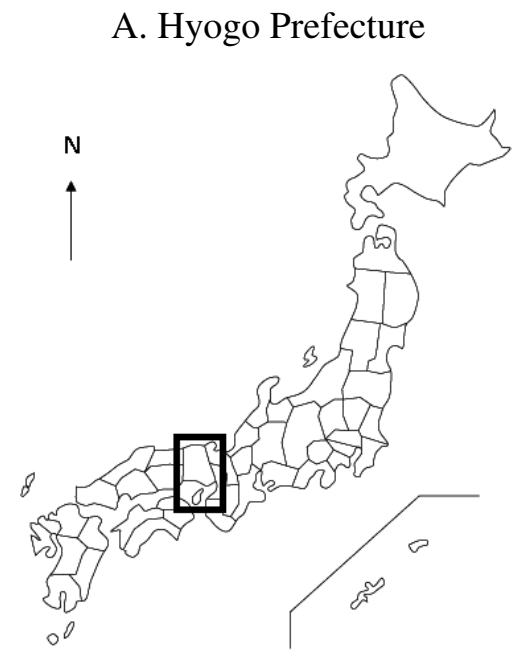

\section{B. The Epicenter}

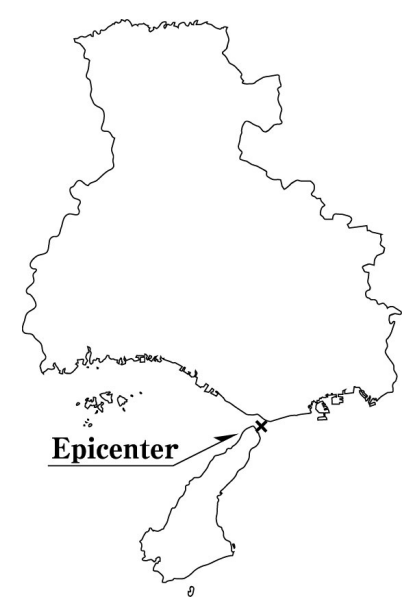

The square in Panel A indicates the location of Hyogo Prefecture in Japan. The cross in Panel B shows the location of the epicenter within Hyogo Prefecture.

Fig. 1. Hyogo Prefecture and the epicenter.

During 1,500 years that earthquakes had been recorded in Japan, Kobe had never been hit by major earthquakes, lending credibility to the notion that the city was safe from seismic activity (United Nations Center for Regional Development, 1995). Local governments, businesses and private households did not anticipate a large earthquake in this area and were not prepared for this large shock. For example, only three percent of property in the Kobe area was covered by earthquake indemnity as opposed to 16 percent in Tokyo (Edgington, 2010). Thus, the earthquake arguably provides an ideal natural experiment that generates exogenous variation in volunteering.

Shortly after the earthquake, a large number of volunteers from different parts of Japan gathered in the disaster area to provide emergency support, such as transporting relief, managing emergency shelters, and providing meals and nursing. A total of 1,377,000 people volunteered over the year following the earthquake, approximately 70 percent of whom were volunteering for the first time (Fire Service and Disaster Prevention Devision, 1996). Their activities attracted the attention of the media and were broadcast across Japan. Volunteering has become a popular activity among the public since then, as is demonstrated by the fact that the year 1995 is called "Volunteer Gannen", meaning "the starting year of volunteerism". 4

In this paper, I focus on the volunteers registered with or known to the Hyogo Council of Social Welfare..$^{5}$ These volunteers engage in activities that primarily target the elderly residing

\footnotetext{
${ }^{4}$ Although volunteer activities had been taking place even before 1995, the activities were mainly conducted by people in, for example, certain religious or political groups and were not necessarily popular activities among the public.

${ }^{5}$ There are individuals not registered with the Hyogo Council of Social Welfare but known to volunteer. They
} 
in their own local communities (Hyogo Council of Social Welfare, 1997). As of 2000, approximately 83 percent of the volunteer activities target the elderly at home, while the rest targets the disabled and individuals in hospitals and care homes. The primary activities of the volunteers are the delivery of meals, visits to houses, hospitals and care homes for a chat, the organization of community gatherings, and assistance with daily tasks (e.g., housework). Figure 2 summarizes the characteristics of volunteers. As shown in Panel A, the vast majority of volunteers are female. Panel B indicates that individuals in their 60s account for the largest proportion of volunteers, 25.4 percent. People in their 50s are the second largest, 23.2 percent, implying that these two age bands account for approximately half of the volunteers. Presumably, females in these age bands have already completed child rearing and are devoting part of their time to volunteering. Panel $\mathrm{C}$ presents the occupational composition of volunteers. A noticeable feature of the occupational composition is that housewives alone account for nearly half of volunteers.

\section{Identification Strategy}

I now turn to a discussion of the identification strategy. This study explores the causal effect of volunteering on mortality by regressing mortality on a measure of volunteering, controlling for various socio-economic indicators. The following model is specified:

$$
\ln (\# \text { deaths })_{i t}=\beta_{0}+\beta_{1} \ln (\# \text { volunteers })_{i t}+X_{i t}^{\prime} \gamma+v_{i}+\tau_{t}+\varepsilon_{i t}
$$

where $\ln (\# \text { deaths })_{i t}$ represents the logged number of deaths in municipality $i$ in year $t$, and $\ln$ (\#volunteers $)_{\text {it }}$ is the logged number of volunteers. The time varying socio-economic characteristics, $X_{i t}$, and the parameter $\gamma$ are $K \times 1$ vectors, where $K$ is the number of socio-economic indicators. $v_{i}$ and $\tau_{t}$ are municipality and year fixed effects, respectively, and $\varepsilon_{i t}$ is the disturbance term.

The main coefficient of interest is $\beta_{1}$ which measures the effect of volunteering on mortality. An econometric issue in the estimation of equation (1) is the endogeneity of volunteering. Specifically, unobserved heterogeneity such as the quality of local health care services may affect both mortality and the level of volunteering. It may also be the case that there are more volunteers in municipalities with a large number of vulnerable individuals such as the elderly (reverse causality). If it is the case, the OLS estimator for $\beta_{1}$ is biased. More precisely, a possible negeative effect of volunteering on mortality is positively biased, resulting in a bias towards zero. An unbiased

are members of community organizations such as women's associations, neighborhood councils, students associations, local elderly clubs, etc. There may well be other volunteers not registered with and not known to the council. Possible implications of unregistered and unknown volunteers will be discussed in Section 5. 
A. Sex

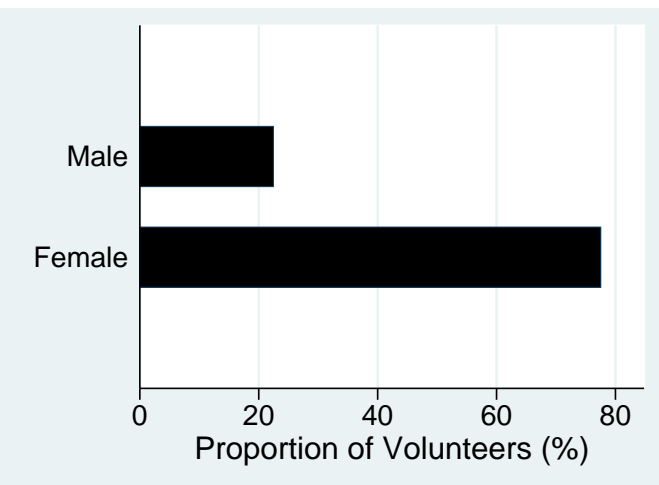

B. Age

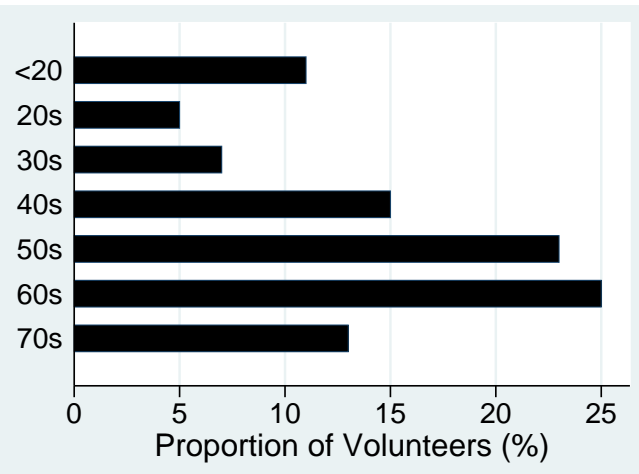

C. Occupation

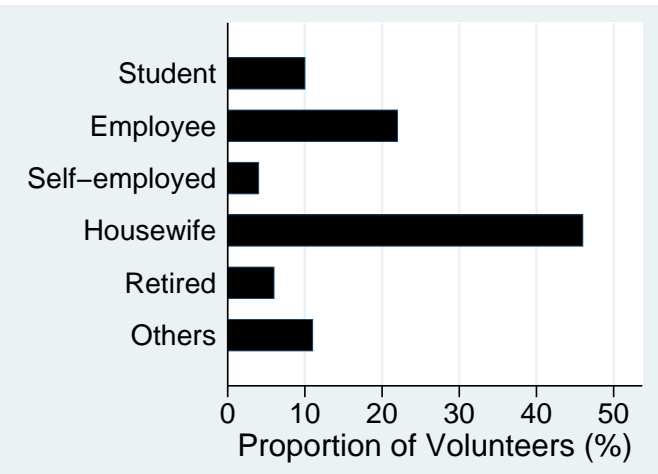

Fig. 2. Volunteer characteristics. 
estimator can be obtained by using the instrumental variable (IV) estimator, which requires an instrument giving exogenous variation in volunteering.

In this paper, physical damage caused by the earthquake is used as an instrument for volunteering. For the physical damage to be a valid instrument, I require the assumption that, conditional on volunteering, the physical damage has no direct effect on mortality. However, the nature of the instrument raises several concerns about the validity of the assumption. Firstly, 6,434 people were killed by the earthquake, and thus the identifying assumption does not hold in the year 1995 . Secondly, apart from the accidental deaths due to the earthquake, chronic illnesses may have deteriorated due to earthquake-related disruptions to daily life (e.g., living in emergency shelters). Thirdly, public resources provided subsequent to the earthquake may have also affected mortality. In order to address these types of concerns, two strategies are employed. I firstly omit the year 1995 and secondly omit severely damaged municipalities from the sample.

Omitting the year 1995 would address the temporary change in mortality in the aftermath of the earthquake. The earthquake occurred in January 1995, and the peak number of 316,678 persons were displaced in January 1995. The number of displaced persons steadily decreased as the (re)construction of homes and temporary housing proceeded, and 97 percent of displaced persons left emergency shelters by August 1995. The earthquake also caused serious damage to infrastructure such as water, electricity, gas supplies and phone lines. ${ }^{6}$ However, repairs of the infrastructure were extremely rapid. Electricity and phone lines were repaired by the end of January 1995, and water and gas supplies resumed by the end of April 1995. The earthquake also severely damaged medical facilities. As of January 1995, 33 percent of hospitals and clinics in Hyogo Prefecture were closed due to damage to buildings or disruptions in infrastructure. Within a month, however, 70 percent of hospitals and clinics had resumed operations, and subsequently 93 percent had resumed operations by the end of 1995. Thus, omitting year 1995 from the sample also addresses the possibility of an increase in mortality induced by temporary disruptions to daily life, infrastructure and medical facilities.

Nevertheless, there may still be a concern that the damage caused by the earthquake had longterm consequences on mortality even after omitting year 1995. For instance, the earthquake may have disproportionately killed frail individuals such as the elderly, leading to a lower mortality afterward because relatively fitter individuals survived. It could also be the case that the mental stress caused by the earthquake and public resources provided in disaster areas had a persistent effect on mortality even after 1995. To address these concerns, I further restrict the sample and drop the set of municipalities severely damaged by the earthquake, though robustness checks will also be conducted using the full sample to see how sample specifications affect estimation results.

\footnotetext{
${ }^{6}$ Water, electricity and gas supplies were cut off in 69, 50 and 46 percent of the households, respectively, and 478,000 phone lines were cut off immediately after the earthquake. The figure for power outages also includes neighboring Osaka Prefecture.
} 


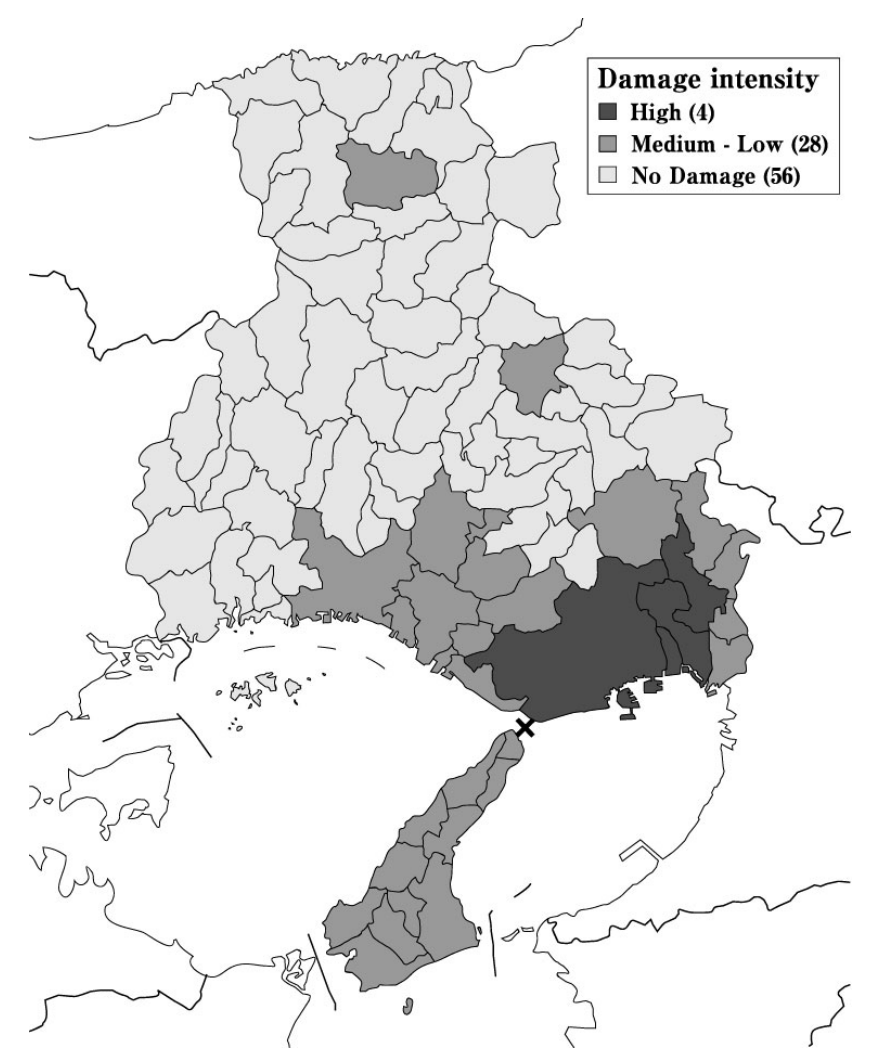

The black area is a subset of municipalities severely damaged by the earthquake and excluded from the sample. The dark gray area corresponds to the treatment group that recorded little to moderate damage, while the light gray area corresponds to the control group that is not hit by the earthquake.

Fig. 3. Earthquake intensity - sample municipalities and omitted municipalities.

Figure 3 shows municipalities in Hyogo Prefecture according to their damage intensity. Among the set of municipalities with damage, the gray area corresponds to a subset of municipalities that recorded little to moderate damage, while the black area corresponds to those severely damaged. ${ }^{7}$ As can be seen, these are the four municipalities closest to the epicenter, which account for a substantial amount of the physical damage due to the earthquake: 98,85 and 88 percent of the total deaths, serious injuries and complete destruction of homes, respectively.

Omitting these municipalities has several important implications. Firstly, most individuals who died due to the earthquake were living in these severely damaged municipalities. If the

\footnotetext{
${ }^{7} \mathrm{~A}$ municipality recorded above the 75 th percentile value of the distribution of a death measure is classified as a severely damaged municipality. The death measure corresponds to the number of deaths caused by the earthquake, such as death by crushing. In Section 6, different definitions of severely damaged municipalities are used.
} 
Table 1: Earthquake damage.

\begin{tabular}{lcccc}
\hline \hline & \multicolumn{2}{c}{ Treatment } & \multicolumn{2}{c}{ Control } \\
\cline { 2 - 5 } & \multicolumn{2}{c}{28 municipalities } & \multicolumn{2}{c}{56 municipalities } \\
\cline { 2 - 5 } & Mean & Std. Err. & Mean & Std. Err. \\
& & & & \\
& 0.06 & 0.03 & 0.00 & 0.00 \\
Deaths per 1,000 pop & 5.45 & 3.05 & 0.00 & 0.00 \\
Injuries per 1,000 pop & 114.35 & 65.28 & 0.00 & 0.00 \\
Destroyed hh per 1,000 hh & & & & \\
\hline \hline
\end{tabular}

Notes: Mean refers to weighted means where weights are population. Variable labels indicate the following: number of deaths per 1,000 persons, number of individuals injured per 1,000 persons, and the number of households whose homes were destroyed per 1,000 households.

earthquake disproportionately killed vulnerable individuals, it would thus have happened in these omitted municipalities. Likewise, if the mental stress caused by, for example, experiencing a large number of deaths in a neighborhood or loosing homes had a long-term effect on mortality, it would have affected mortality in the omitted municipalities. Secondly, as mentioned previously, medical facilities were heavily damaged, a large number of individuals were displaced, and public resources were provided in the disaster areas subsequent to the earthquake, which may have had long-term consequences on mortality. Omitting municipalities heavily damaged by the earthquake addresses these types of concerns, as emergency shelters, medical facilities that experienced severe damage, and the areas targeted for providing extensive public support were concentrated in these omitted municipalities. ${ }^{89}$

Table 1 presents the average destruction due to the earthquake in the treatment and control municipalities. A municipality is categorized as treated if the municipality recorded a positive level of physical damage due to the earthquake. Thus, the average destruction in control municipalities is equal to zero by construction. After omitting the four most severely damaged municipalities, my sample consists of 28 municipalities in the treatment group and 56 municipalities in the control group. Table 1 indicates that approximately 0.5 percent of people were injured and approximately 10 percent of households had their homes damaged in the treatment municipalities. As expected, the share of individuals who died, 0.006 percent, is not substantial because severely damaged municipalities are excluded.

\footnotetext{
${ }^{8}$ As of 1995, approximately 98 percent of displaced persons, 99 percent of the hospitals and clinics that were closed, and 91 percent of public expenditure on disaster relief were concentrated in these omitted municipalities.

${ }^{9}$ Section 6 will explicitly account for healthcare capacity and the provision of public resources as robustness checks.
} 


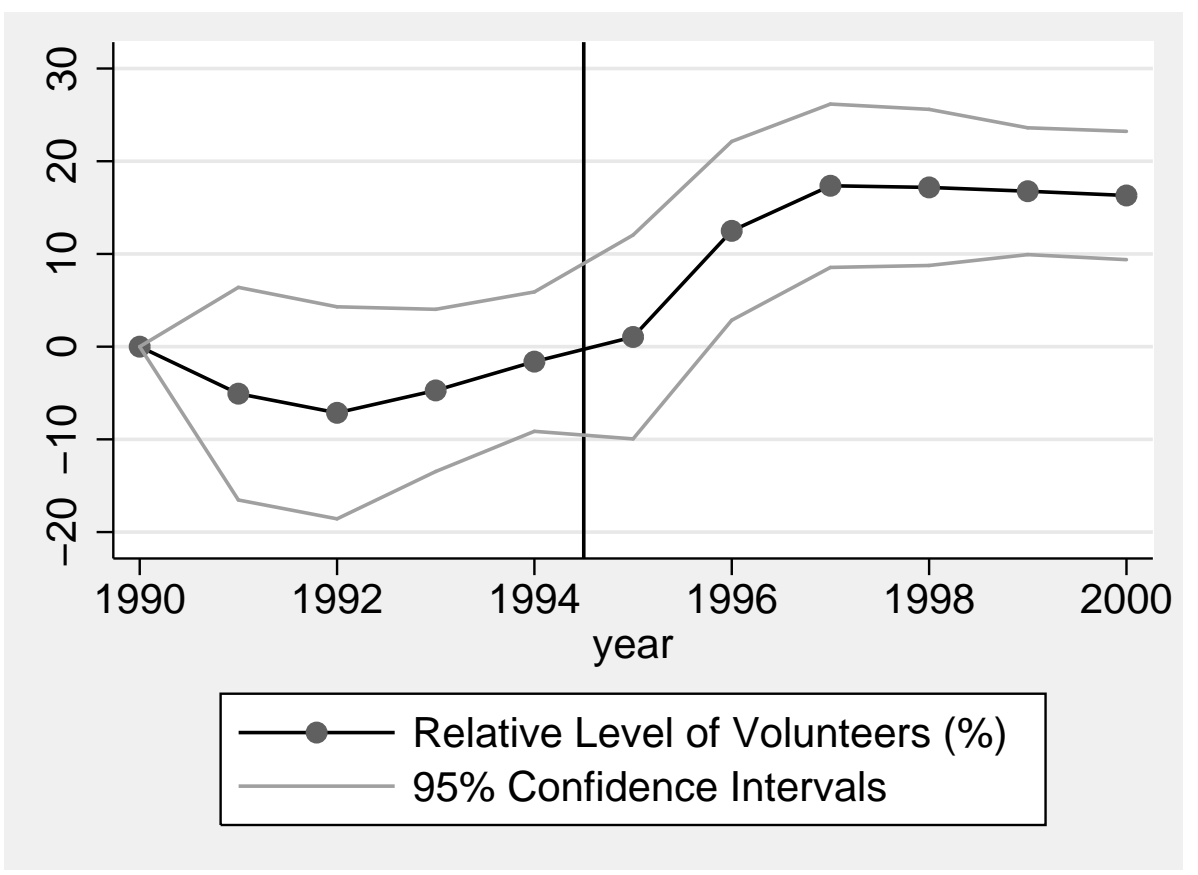

Fig. 4. Relative level of volunteers in the treatment municipalities to the control municipalities.

For the earthquake damage to be a valid instrument, it must be correlated with volunteering. Figure 4 plots the level of volunteers in the treatment group relative to the control group. For example, the relative level of volunteers plotted on the y-axis equals 10 if the number of volunteers in the treatment group was 10 percent higher, and it equals zero if there is no difference in the number of volunteers between the two groups. The graph shows that there was a lower level of volunteers in the treatment municipalities before the earthquake in 1995, although the difference is not significantly different from zero. In contrast, the level of volunteers sharply increased after the earthquake by approximately 15 percent and stayed at the higher level, implying that the earthquake caused a persistent rather than a temporary increase in the level of volunteers. ${ }^{10}$

To identify the causal effect of volunteering, it is important that the treatment and control municipalities had similar characteristics prior to the earthquake. Table 2 compares the preearthquake characteristics of the two groups. Panel A indicates that there is no important difference in sex and age compositions, the divorce rate and the widowed rate. Although treated

\footnotetext{
${ }^{10}$ The relative level of volunteers in the year 1995 between the two groups is not significantly different from zero. This is not surprising given that the earthquake occurred in January 1995 and the number of volunteers was recorded in March 1995, implying that presumably not enough time had passed since the earthquake occurred.
} 
Table 2: Municipality characteristics.

\begin{tabular}{|c|c|c|c|c|c|}
\hline & \multicolumn{2}{|c|}{ Treatment } & \multicolumn{2}{|c|}{ Control } & \multirow[b]{3}{*}{ p-value } \\
\hline & \multicolumn{2}{|c|}{28 municipalities } & \multicolumn{2}{|c|}{56 municipalities } & \\
\hline & Mean & Std. Err. & Mean & Std. Err. & \\
\hline \multicolumn{6}{|l|}{ A. Demography } \\
\hline Sex ratio & 0.97 & 0.12 & 0.93 & 0.05 & 0.75 \\
\hline$\%$ Pop under 15 & 18.70 & 5.14 & 19.08 & 2.11 & 0.97 \\
\hline$\%$ Pop over 65 & 11.14 & 2.95 & 16.03 & 1.55 & 0.55 \\
\hline$\%$ Divorced & 2.44 & 0.86 & 1.76 & 0.23 & 0.83 \\
\hline$\%$ Widowed & 7.38 & 2.01 & 10.24 & 1.04 & 0.67 \\
\hline In-migration per 1,000 pop & 46.07 & 5.51 & 32.25 & 1.87 & 0.48 \\
\hline Out-migration per 1,000 pop & 44.92 & 6.02 & 34.34 & 1.82 & 0.59 \\
\hline \multicolumn{6}{|l|}{ B. Education } \\
\hline$\%$ Compulsory & 22.45 & 6.15 & 31.54 & 2.96 & 0.39 \\
\hline$\%$ High school & 33.44 & 9.73 & 30.22 & 3.67 & 0.76 \\
\hline$\%$ University & 14.89 & 4.44 & 10.15 & 1.31 & 0.52 \\
\hline \multicolumn{6}{|l|}{ C. Economy } \\
\hline \% Unemployed & 1.68 & 0.56 & 1.21 & 0.17 & 0.86 \\
\hline$\%$ Employed & 47.42 & 13.61 & 48.21 & 5.27 & 0.95 \\
\hline Income per cap & 1,400 & 177 & 1,128 & 61 & 0.07 \\
\hline Medical exp per cap & 637 & 84 & 516 & 27 & 0.09 \\
\hline
\end{tabular}

Notes: Mean refers to weighted means where weights are population. Figures are the average over the pre-earthquake period, i.e., year $<1995$. The p-value corresponds to p-values of tests under the null hypothesis of equality of means or proportions between the treatment and control groups. The sex ratio corresponds to number of males relative to females. \% divorced and \% widowed are defined for individuals aged 15 or above. Per capita taxable income and public medical expenditures on the elderly are measured in $¥ 1,000$. 


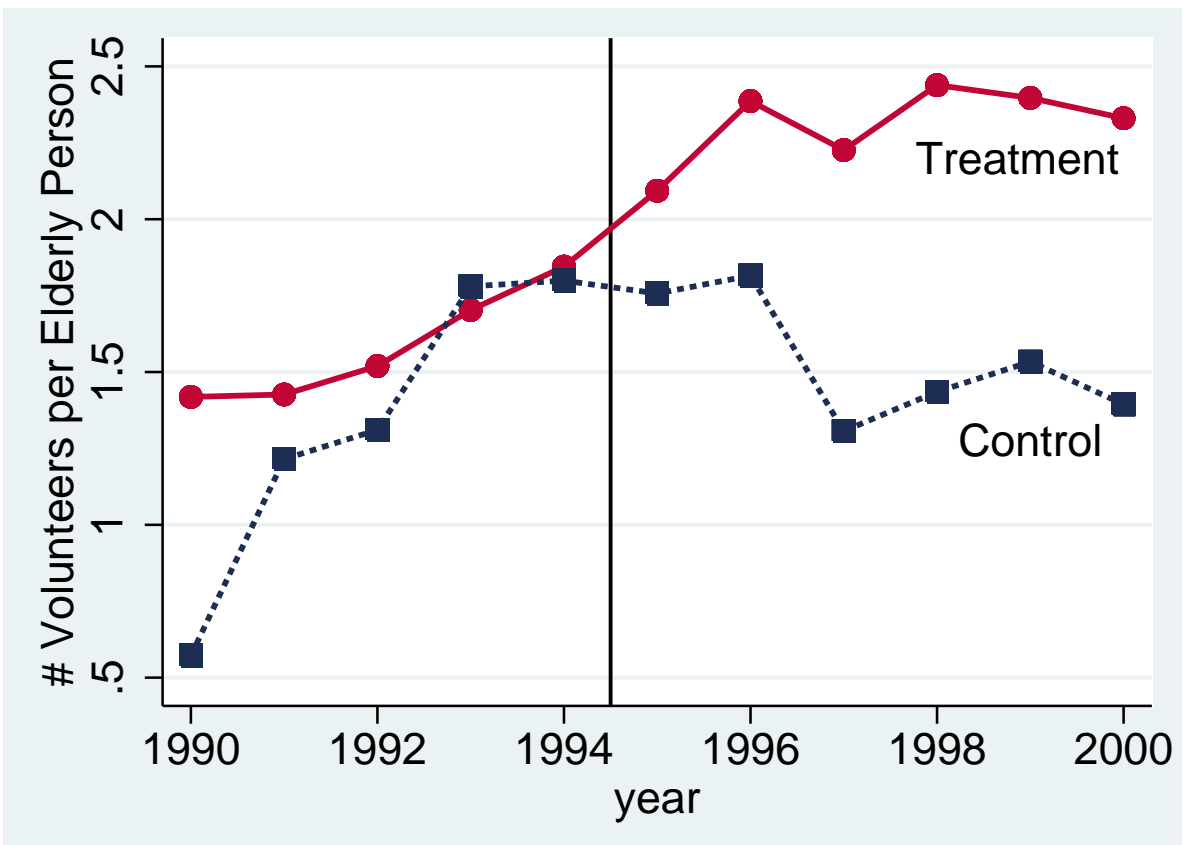

Fig. 5. VOLUNTEERS PER ELDERLY PERSON

Notes: Two series correspond to the weighted-average number of volunteers per individual aged 80 or older. The weight is earthquake damage.

municipalities display higher in-migration and out-migration rates, the rates are not statistically different between the two groups. Panel B suggests that the level of educational attainment is higher in the treatment group, but the difference is not statistically significant. With respect to characteristics related to the labor market and the economy (Panel C, Table 2), the unemployment and employment rates are similar in the two groups. Per capita income and public medical expenditures on the elderly are higher in the treatment group, but the differences are again not statistically significant.

The identification of the effect of volunteering also requires that trends in the treatment and control groups were the same prior to the earthquake. Figure 5 plots the number of volunteers per elderly person in the two groups. Figure 5 indicates that the control municipalities exhibited a steeper upward trend prior to the earthquake, which potentially underestimates the effect of earthquake damage on volunteering. After the earthquake, trends in the number of volunteers between the two groups diverge, and the treatment municipalities exhibit a higher number of volunteers per elderly person. Although there seems to be dips in the two series in 1997, a shock to volunteering that equally affects the two groups is absorbed by year fixed effects. Note that, 
at a glance, it may be counterintuitive that the volunteer rate in the control group flattened out after the earthquake. However, given that the control group did not experience any earthquake damage, the volunteer rate in the treatment group would have also flattened out in the absence of the earthquake.

Turning to mortality, Figure 6 plots the mortality rate by age cohort. The mortality rate is expressed per 1,000 individuals in the corresponding age cohort. For a comparison purpose, the mortality rate of the set of municipalities that recorded a positive level of earthquake damage, including severely damaged municipalities, is also reported. Not surprisingly, Figure 6 shows sharp spikes in the year of the earthquake, 1995, regardless of age cohort for the set of municipalities with a positive level of earthquake damage. As expected, however, after excluding the severely damaged municipalities from the sample, the treatment group does no longer exhibit the sharp spikes in 1995. Prior to the earthquake, the mortality rates between the treatment and control groups exhibited downward trends in every age cohort with higher mortality rates in the treatment group. The higher pre-earthquake mortality rates observed in the treatment group do not invalidate the identification because the systematic differences between the two groups are absorbed by municipality fixed effects. After the earthquake, the mortality rate of people in their $60 \mathrm{~s}$ and $80 \mathrm{~s}$ or older in the treatment group appears to have decreased to a greater extent, while such a pattern was not observed in other age cohorts.

\section{Data and Variables}

My sample consists of observations for 84 municipalities in Hyogo Prefecture from 1990 to 2000. Data on mortality and divorce are obtained from the Current Population Survey (Jinko Dotai Chosa) conducted every year by the Ministry of Health, Labor, and Welfare. The survey has been conducted since 1898 and collects data on births, deaths, stillbirths, marriages and divorces.

Data on volunteering are available from the Hyogo Council of Social Welfare Activity Report (Kennai Syakyo Katsudo Genkyo Chosa). The report provides various figures related to volunteering, such as the number of volunteers and voluntary groups at the municipality level in Hyogo Prefecture. These volunteers engage in activities that primarily target the elderly residing in their own local communities. Characteristics of care receivers, problems and challenges that volunteer activities face are also described in the report, which provides a detailed and useful source of information on volunteering and is available from 1990 onwards. However, the descriptions of the characteristics of volunteers and volunteer activities are rather narrative in nature, and thus it is difficult to provide their statistical overview. I therefore also extract data on volunteer characteristics and the contents and frequency of volunteer work from the Report on the Trend in Volunteer Activity (Volunteer Katsudo Doko Chosa Hokokusyo), which is a report on a survey of volunteer- 
Panel A. Mortality rate, 50s

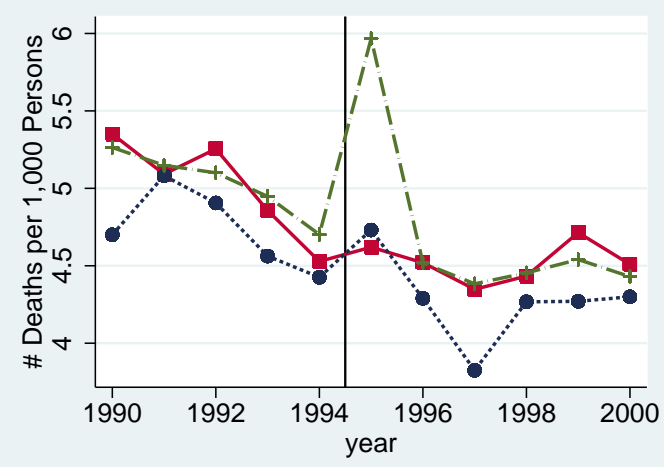

Panel C. Mortality rate, 70s

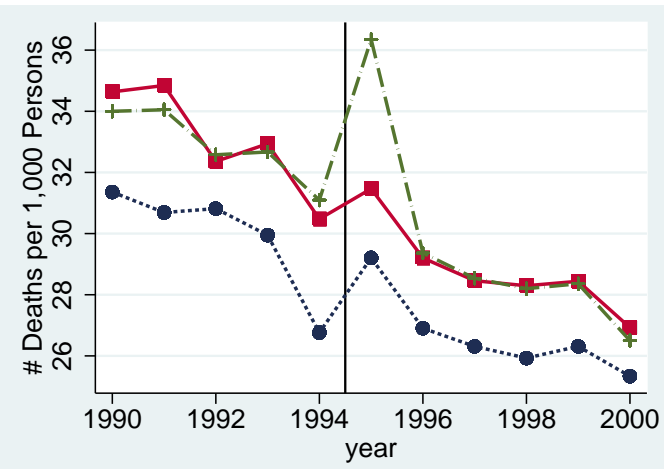

Panel B. Mortality rate, 60s

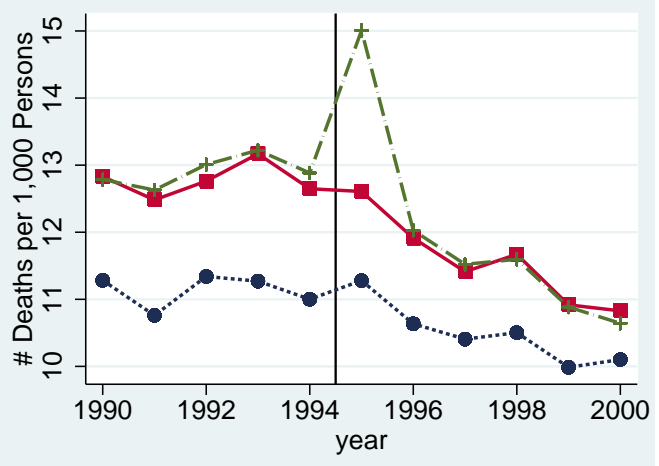

Panel D. Mortality rate, $80+$

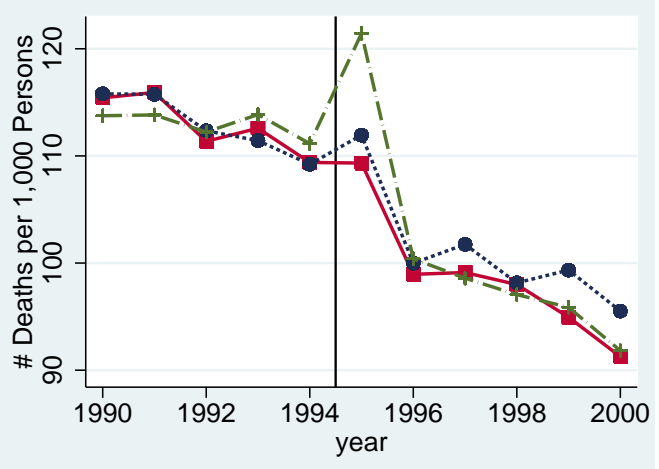

Fig. 6. MORTALITY RATE BY AGE COHORT

Notes: Each series represents the weighted average number of deaths per 1,000 persons. Weights are the population in the corresponding age cohort. 
ing in Hyogo Prefecture that has been conducted every four years since 1984. The survey collects various information on volunteering such as the sex, age, and occupation of volunteers, frequency of volunteer activity and financial conditions of voluntary groups, etc.

Information on the physical damage due to the earthquake is provided by the Disaster Prevention Division of Hyogo Prefecture. The document reports physical damage due to the earthquake officially confirmed by the Fire and Disaster Management Agency of the Ministry of Internal Affairs and Communications. Earthquake damage is categorized into injuries, deaths and damage to buildings, and each category is further divided into sub-categories according to the extent of the damage.

Public medical expenditures on the elderly are obtained from the National Health Insurance and Health Insurance for the Aged in Hyogo (Hyogo no Kokuho Rouken). The document summarizes public expenditures related to health at the municipality level in Hyogo Prefecture. Information on donations of money to charity is provided by the Hyogo branch of the Japanese Red Cross. The data is on money donated to the Japanese Red Cross and is available from 1989 onwards at city and regional levels in Hyogo Prefecture. The regional level data is decomposed into town level using town population as a weight.

Data on covariates other than public medical expenditures and divorce are obtained from a survey report, the System of Social and Demographic Statistics of Japan (Syakai Jinko Tokei Taikei). The survey covers every municipality in Japan and collects information on socio-economic and demographic conditions of municipalities. It has been conducted since 1976 and provides 1,500 social and demographic variables by municipality. As socio-economic indicators, I use municipality level measures of economic activity, demography, healthcare expenditure, healthcare capacity, and educational level: taxable income per capita, unemployment rate, sex ratio, age-cohortspecific population, divorce rate, medical expenditures on the elderly per capita, the number of hospitals and clinics per 1,000 population, and high school participation rate. The first lag of population is used because mortality and population in period $t$ are simultaneously determined. Data on the unemployment rate and population by age cohort are available only in census years (i.e., 1990, 1995 and 2000). Thus, values in years other than census years are computed in a manner detailed in the appendix.

\section{Results}

I begin by presenting the OLS estimates of equation (1). Table 3 reports the estimates of regressions in which mortality by age cohort is regressed on municipality and year fixed effects and other controls between 1990 and 2000. The dependent variables in columns (1) to (4) correspond to the logged number of individuals who died in their $50 \mathrm{~s}, 60 \mathrm{~s}, 70 \mathrm{~s}$, and $80 \mathrm{~s}$ or older, respectively. 
Table 3: Effect of volunteering on mortality (OLS estimates).

\begin{tabular}{lcccc}
\hline \hline \multirow{2}{*}{ Dependent variable: } & \# Deaths 50s & \# Deaths 60s & \# Deaths 70s & \# Deaths 80+ \\
\cline { 2 - 5 } & $(1)$ & $(2)$ & $(3)$ & $(4)$ \\
& & & & \\
& -0.017 & 0.013 & 0.007 & -0.008 \\
& $(0.023)$ & $(0.013)$ & $(0.011)$ & $(0.011)$ \\
\hline Controls & yes & yes & yes & yes \\
Municipality FE & yes & yes & yes & yes \\
Year FE & yes & yes & yes & yes \\
\# Observations & 825 & 838 & 838 & 838 \\
\# Municipalities & 84 & 84 & 84 & 84 \\
\hline \hline
\end{tabular}

Notes: Standard errors are clustered by municipality. The dependent variable is the number of agecohort specific deaths. Controls included in the analysis are income per capita, unemployment rate, sex ratio, age-cohort-specific population, divorce rate, medical expenditures on the elderly per capita, high school participation rate, and municipality and year fixed effects. Each variable in levels is logged. Due to missing values, the sample sizes are slightly smaller than $840=84$ municipalities $\times 10$ years.

Table 3 indicates that every coefficient estimate is not significantly different from zero, implying that volunteering had no significant effect on mortality in any age cohort. The OLS estimator is, however, biased if (i) unobserved heterogeneity across municipalities that affects mortality is also correlated with the number of volunteers or (ii) the levels of mortality and volunteers are simultaneously determined. To address the possible endogeneity of volunteering, equation (1) is estimated using the IV estimator.

Table 4 presents the first-stage and reduced-form estimates of the effect of earthquake damage on volunteering and on age-cohort-specific mortality, respectively, and the IV estimates of the effect of volunteering on mortality (i.e., $\beta_{1}$ in equation (1)). Earthquake damage is measured by percentage of individuals injured, though other damage indicators will also be used as robustness checks. The damage indicator is equal to zero in every municipality before the earthquake and takes a positive value, for example 10, throughout the post-earthquake period if 10 percent of the population is injured in a municipality. The first row of each panel corresponds to a specification that controls only for municipality and year fixed effects. The estimates indicate that earthquake damage had positive effects on volunteering, and the effects are highly statistically significant. The first row of each panel is, however, not correctly specified if any difference across municipalities that varies over time affects mortality. To account for time varying heterogeneity across municipalities that may affect mortality, socio-economic indicators are added to the second row of each panel. The results are robust to the inclusion of additional controls, and indicate that a one- 
Table 4: First-stage, reduced-form, and IV estimates of mortality regressions.

\begin{tabular}{|c|c|c|c|c|c|}
\hline \multicolumn{2}{|c|}{ Dependent variable: } & \multirow{2}{*}{$\begin{array}{l}\text { Volunteer } \\
\text { First-stage }\end{array}$} & \multirow[b]{2}{*}{ F-statistic } & \multicolumn{2}{|c|}{ Mortality by age cohort } \\
\hline & & & & Reduced-form & IV \\
\hline Age cohort & Controls & (1) & (2) & (3) & (4) \\
\hline \multirow[t]{2}{*}{ A. $50 \mathrm{~s}$} & no & $\begin{array}{c}0.203^{* * *} * \\
(0.040)\end{array}$ & $\begin{array}{c}25.6 \\
-\end{array}$ & $\begin{array}{c}-0.001 \\
(0.013)\end{array}$ & $\begin{array}{l}-0.005 \\
(0.066)\end{array}$ \\
\hline & yes & $\begin{array}{c}0.196 * * * \\
(0.037)\end{array}$ & $\begin{array}{c}28.3 \\
-\end{array}$ & $\begin{array}{c}-0.005 \\
(0.014)\end{array}$ & $\begin{array}{l}-0.027 \\
(0.071)\end{array}$ \\
\hline \multirow[t]{2}{*}{ B. $60 \mathrm{~s}$} & no & $\begin{array}{c}0.202^{* * *} * \\
(0.040)\end{array}$ & $\begin{array}{c}25.9 \\
-\end{array}$ & $\begin{array}{c}-0.006 \\
(0.011)\end{array}$ & $\begin{array}{c}-0.028 \\
(0.060)\end{array}$ \\
\hline & yes & $\begin{array}{c}0.204 * * * \\
(0.038)\end{array}$ & $\begin{array}{c}28.2 \\
-\end{array}$ & $\begin{array}{l}-0.001 \\
(0.008)\end{array}$ & $\begin{array}{l}-0.005 \\
(0.040)\end{array}$ \\
\hline \multirow[t]{2}{*}{ C. $70 \mathrm{~s}$} & no & $\begin{array}{c}0.202 * * * \\
(0.040)\end{array}$ & $\begin{array}{c}25.9 \\
-\end{array}$ & $\begin{array}{c}-0.026 * * * \\
(0.008)\end{array}$ & $\begin{array}{c}-0.129 * * * \\
(0.023)\end{array}$ \\
\hline & yes & $\begin{array}{c}0.200 * * * \\
(0.039)\end{array}$ & $\begin{array}{c}26.4 \\
-\end{array}$ & $\begin{array}{c}-0.017 * \\
(0.009)\end{array}$ & $\begin{array}{c}-0.085^{* *} \\
(0.038)\end{array}$ \\
\hline \multirow[t]{2}{*}{ D. $80+$} & no & $\begin{array}{c}0.202 * * * \\
(0.040)\end{array}$ & $\begin{array}{c}25.9 \\
-\end{array}$ & $\begin{array}{c}-0.037 * * * \\
(0.005)\end{array}$ & $\begin{array}{c}-0.181 * * * \\
(0.052)\end{array}$ \\
\hline & yes & $\begin{array}{c}0.211^{* * *} \\
(0.040)\end{array}$ & $\begin{array}{c}27.6 \\
-\end{array}$ & $\begin{array}{c}-0.032 * * * \\
(0.006)\end{array}$ & $\begin{array}{c}-0.152 * * * \\
(0.042)\end{array}$ \\
\hline
\end{tabular}

Notes: $* p<.10, * * p<.05$, and $* * * p<.01$. Standard errors are clustered by municipality. First-stage and reduced-form estimates are the estimated coefficients on the damage indicator. The IV estimates are the estimates of $\beta_{1}$ in equation (??). Refer to Table 3 for controls included in the analysis. The sample sizes are 839 and 838 for the regressions without and with controls, respectively, except Panel A (826 without controls and 825 with controls). The F-statistics on the excluded instrument are reported.

percentage-point increase in the percentage of individuals injured raised the number of volunteers by approximately 20 percent on average.

It is important for the identification that the instrument is not weak, meaning that the instrument and the level of volunteering are highly correlated. A weak instrument is known to bias the IV estimator toward the probability limit of the corresponding OLS estimator. Stock et al. (2002) compute the critical value for the weak instrument test based on the first-stage F-statistic and suggest that an F-statistic above approximately 10 makes IV inferences reliable. Note in this regard that the F-statistics on the excluded instrument reported in column (2) exceed 10. Thus, according to their test for weak instruments, the instrument is not weak.

The reduced-form estimates in column (3) show that a higher rate of earthquake damage was 
significantly associated with lower mortality rates of people in their 70 s and 80 s or older. Finally, the causal effect of interest reported in column (4) indicates that volunteering had no significant effect on the mortality of people in their 50 s and 60 s, while it significantly reduced mortality among people in their 70 s and 80 s or older. ${ }^{11}$ The significance of the estimates remains unchanged after adding socio-economic indicators as controls. The estimated causal effect is -0.152 (column (4), Panel D), meaning that a one-percent increase in the number of volunteers reduced mortality among people in their 80 s or older by approximately 0.15 percent on average. Evaluated at the mean, the estimate implies that the life of roughly one person aged 80 or older (out of 125 persons) was saved in a given year when the number of volunteers increased by 100 (out of 1,389 persons). Conditional on living until 80 or older, a one-year extension of life is a substantial increase, corresponding to an approximately 11 percent increase in life expectancy. ${ }^{12}$

Having estimated the elasticity of mortality with respect to the number of volunteers, it is informative to know the number of hours of volunteer work to assess the size of the estimated elasticity. Unfortunately, data on the intensity of volunteer work are very limited. Nevertheless, using data on frequency and contents of volunteer work, I compute the number of hours worked per volunteer. Details of this computation can be found in the appendix. The estimate indicates that a volunteer works approximately 88 hours per annum, implying that 100 additional volunteers correspond to roughly 8,800 hours of labor. How much do this volunteer hours cost in terms of the opportunity cost of labor? As the majority of volunteers are not in the labor force (e.g., housewives), the opportunity cost of volunteer work is unclear; thus, I use the minimum wage in Hyogo Prefecture to evaluate their opportunity cost. Evaluated at the minimum wage, 8,800 hours of labor cost $\$ 48,015$, implying that it costs approximately $\$ 48,015$ to save the life of an individual aged 80 or older in a given year. ${ }^{13}$

My estimates capture the net effect of volunteering on mortality and thus do not allow me to determine whether the reduction in mortality is driven by that of volunteers or care recipients. The reduction in mortality among people in their 80 s or older is, however, likely to have occurred among recipients given that every volunteer was younger than 80 (Hyogo Council of Social Welfare, 1997). The effect on people in their 70s is inconclusive given that 13 percent of volunteers are in their 70s. However, it is likely that the reduction in mortality occurred among care recipients

\footnotetext{
${ }^{11}$ As previously mentioned, the measure of volunteering does not capture volunteers not registered with or not known to the Hyogo Council of Social Welfare. The presence of the unregistered or unknown volunteers can affect the results in Table 4 if the propensity to register or to be recognized by the council was correlated with elderly mortality and differed between the treatment and the control groups. Unfortunately, it is impossible to further investigate this possibility due to data limitation. However, it is worth noting that the presence of the unregistered or unknown volunteers does not invalidate the story that volunteers reduced elderly mortality, although it affects the interpretation of the estimates.

${ }^{12}$ Life expectancy at age 80 in Hyogo Prefecture was 9.25 years in 2000. The calculation of life expectancy can be found in the appendix.

${ }^{13}$ The interpretation of the estimated cost of volunteer labor is subject to the several caveats detailed in the appendix.
} 
because volunteers are presumably fitter than care recipients. This inference is further strengthened by the fact that volunteering had no significant effect on the mortality of people in their 50s and 60s. As roughly half of volunteers were aged between 50 and 69, a reduction in mortality of people in their 50s and 60s would be observed if volunteering reduced the mortality of volunteers themselves. ${ }^{14}$

It has been established that volunteering reduced mortality among the elderly. However, the results are not informative regarding the mechanisms through which volunteering affects mortality. To infer the operating mechanisms, I regress cause-specific mortality on volunteering. ${ }^{15}$ Although it is at best suggestive evidence, examining the types of deaths affected by volunteering would help to narrow down the potential operating mechanisms. Several possible channels are discussed below. Firstly, it may be the case that volunteering enhances social contact (e.g., Oman et al., 1999) and more social contact subsequently leads to better health and reduced mortality risk (House et al., 1988). Interactions with volunteers may encourage positive emotions, such as happiness and a sense of security, which serves to reduce stressors and thereby improve the health status of an individual. The link between stressors and health status is well documented. For example, Kiecolt-Glaser and Glaser (1995) find evidence that stressors affect the strength of the immune system, which in turn influences the progression of cancer and infectious diseases.

Secondly, using volunteer services means that someone visits the elderly regularly, implying that the elderly are found relatively quickly when they need an emergency help because, for example, they suffer from acute diseases (e.g., a stroke) or had an accident at home. This is a potentially important channel, as "kodokushi", meaning "dying alone", is an important social issue among the elderly in Japan. More precisely, since the 1970s, there have been numerous accidents in which the elderly living alone were found dead in their homes some time after they had passed away. The Ministry of Health, Labor and Welfare launched a project to combat "kodokushi", and a project report highlights the importance of social contact as a means to prevent the elderly from dying alone at home. In a similar vein, regular visits by volunteers also imply that the elderly are provided with substantial care. Recalling that one of the main activities of volunteers is to provide meals, volunteers may help the elderly to have well-balanced meals, which may subsequently improve their general health conditions.

\footnotetext{
${ }^{14}$ The estimates in Table 4 capture the contemporaneous effect of volunteering on mortality; therefore, they reflect the short-run effect of volunteering. Table 4 indicates that the short-run mortality of individuals in their $50 \mathrm{~s}$ and $60 \mathrm{~s}$ is not affected by volunteer work. This, however, does not exclude the possibility that volunteering affects the mortality of those in their 50s and 60s later in life.

${ }^{15}$ In the cause-specific mortality data, there are observations that equal zero, for which the logged values are not defined. I therefore recode zero to one and take the log of the recoded values to make the coefficient estimates comparable to the main results. Additionally, for types of cause of death that have numerous zero values, namely diabetes and high blood pressure, I consider two different functional form specifications: (i) raw values of mortality and (ii) an indicator variable that equals one if a municipality recorded a positive value of mortality and zero otherwise. The results are not sensitive to the specifications of functional forms.
} 
Table 5: Effect of volunteering on mortality by cause of death (IV estimates).

\begin{tabular}{lcccccccc}
\hline \hline Cause of death: & $\begin{array}{c}\text { Cerebral } \\
\text { vascular } \\
\text { disease }\end{array}$ & $\begin{array}{c}\text { Heart } \\
\text { disease }\end{array}$ & Decrepitude & Cancer & $\begin{array}{c}\text { High } \\
\text { blood } \\
\text { pressure }\end{array}$ & Pneumonia & Diabetes & Accident \\
\cline { 2 - 15 } & $(1)$ & $(2)$ & $(3)$ & $(4)$ & $(5)$ & $(6)$ & $(7)$ & $(8)$ \\
\hline & $-0.265 * * *$ & $-0.189 * * *$ & $-0.297 * *$ & -0.055 & -0.055 & -0.055 & -0.016 & 0.091 \\
& $(0.077)$ & $(0.065)$ & $(0.128)$ & $(0.042)$ & $(0.088)$ & $(0.064)$ & $(0.160)$ & $(0.071)$ \\
\hline Controls & yes & yes & yes & yes & yes & yes & yes & yes \\
\# Observations & 838 & 838 & 838 & 838 & 838 & 838 & 838 & 838 \\
\# Municipalities & 84 & 84 & 84 & 84 & 84 & 84 & 84 & 84 \\
\hline \hline
\end{tabular}

Notes: $* * p<.05$ and $* * * p<.01$. Standard errors are clustered by municipality. The dependent variable is the logged number of cause-specific deaths. Refer to Table 3 for controls included in the analysis.

Table 5 reports the IV estimates of the effect of volunteering on cause-specific mortality. ${ }^{16}$ The results indicate that volunteering significantly reduced mortality caused by cerebral vascular disease, heart disease and decrepitude but had no significant effect on mortality caused by cancer, high blood pressure, pneumonia, diabetes or accidental death. Many diseases categorized as cerebral vascular disease and heart disease are acute diseases such as stroke, intracerebral bleeding and heart attack. Thus, volunteering may have reduced mortality caused by these diseases by providing quicker access to medical assistance when the elderly suffered from acute diseases. The inference is further strengthened by the finding that volunteering had an insignificant effect on mortality caused by high blood pressure and diabetes, which are some of the main causes of cerebral vascular disease and heart disease. If volunteering reduced mortality by helping the elderly to recover from cerebral vascular disease and heart disease, it would have also affected mortality due to illnesses that caused these diseases. Furthermore, as the estimates in Table 5 are those of the short- to medium-term effects of volunteering, it would not be plausible that mortality caused by these serious diseases is affected by volunteers in the short run. The significant reduction in mortality caused by decrepitude means that the elderly with no particular known disease lived longer. A possible interpretation is that volunteers helped to improve the general health conditions of the elderly by providing them with well-balanced meals, reminding them to take medicine, or helping them to engage in exercise when they might otherwise have been confined to bed.

Mortality caused by illnesses documented to be affected by an improvement in the strength of

\footnotetext{
${ }^{16} \mathrm{~A}$ caveat is that data on mortality by cause of death are available by municipality but not by age. As types of mortality prevalent among younger individuals, such as those related to childbirth or suicide, are irrelevant to my analysis, I run regressions only on types of mortality prevalent among individuals in their 70s or older.
} 
the immune system, such as cancer, high blood pressure and infectious diseases (pneumonia), was not affected by volunteering. The results imply that the reduced stress channel is unlikely to be an operating mechanism. ${ }^{17}$ Volunteering also had no statistically significant effects on diabetes. Diabetes can be caused by stress, genes, malnutrition and obesity. Volunteering could potentially reduce mortality caused by diabetes via improved nutritional status among the elderly, but the process would take a longer period of time than what is currently examined. The insignificant effect on accidental deaths seems plausible. One of the main causes of accidental deaths is traffic accidents. As most volunteer activities take place indoors (e.g., the delivery of meals), accidental deaths are unlikely to be relevant to volunteering. Alternatively, my measure of mortality due to accidents may not be sufficiently precise to capture the effects of volunteering on accidental deaths among the elderly, as approximately 40 percent of individuals who died due to accidental deaths were younger than 70 years of age.

\section{Robustness Checks}

In this section, to establish that the main results are not driven by unobserved factors correlated with volunteering that reduce mortality, such as general altruism, I firstly control for their proxy and also conduct a series of falsification exercises. Secondly, this section investigates whether the main findings in the previous section are driven by omitting relevant variables, such as healthcare capacity and public spending on disaster relief. Thirdly, further falsification exercises are conducted to ensure that the observed increase in volunteering is not spurious. Finally, I examine the robustness of the results to different sample specifications and damage measures as instruments.

Firstly, unobserved factors such as general altruism and social cohesion may have changed in the wake of the earthquake, and these factors, plausibly correlated with the level of volunteering, can provide alternative explanations for the previous findings. To address this concern, two strategies are employed. Firstly, I control for general altruism proxied by donations of money to charity. The inclusion of this variable would disentangle the effect of unpaid labor from that of general altruism. Panel A1 of Table 6 indicates that the results are not sensitive to the inclusion of the proxy of general altruism: earthquake damage significantly raised the level of volunteering, which subsequently reduced the mortality of individuals in their $70 \mathrm{~s}$ and $80 \mathrm{~s}$ or older. The reduced-form estimates in Panel A1 also show that a higher rate of earthquake damage was significantly associated with lower mortality rates of people in their 70s and 80s or older. Secondly, the mortality of children and young adults is regressed on volunteering. If unobserved factors such as those mentioned above drive the main results, they would also affect the mortality of age bands

\footnotetext{
${ }^{17}$ An important caveat for the interpretation of the estimates in Table 5 is that these are short- to medium-term effects. Insignificant effects on mortality caused by cancer, high blood pressure, diabetes and pneumonia in the short run do not exclude the possibility that volunteering affects mortality caused by these diseases in the longer term.
} 
other than the elderly. In contrast, if it is indeed volunteering that drives the main results, it would not affect the mortality of children and young adults as the volunteering in question targets the elderly. Panel B of Table 6 regresses the mortality of four different age bands, 0 - 9 to 30 - 39, on volunteering. ${ }^{18}$ Panel $\mathrm{B}$ indicates that the first-stage estimates are highly statistically significant, while there was no significant effect of volunteering on the mortality of children and young adults. The reduced-form estimates also confirm that earthquake damage had no significant effect on the mortality of children and young adults. Thus, the results do not support the possibility that the main findings are driven by unobserved factors correlated with volunteering.

Secondly, one may be concerned that the main results are driven by changes in healthcare capacity and the provision of public resources subsequent to the earthquake. For example, government spending increased in the treatment municipalities after the earthquake, and some of this increased spending may have been allocated to the healthcare sector. Mortality in the treatment municipalities may have decreased because hospitals and clinics benefited from an increase in their healthcare capacity (e.g., newer equipment, more health care professionals, etc.) relative to the control municipalities. This concern is likely to be (at least partly) addressed by omitting the severely damaged municipalities because most damaged medical facilities and a significant proportion of public spending on disaster relief were concentrated in the omitted municipalities. In addition, public medical expenditures that specifically target the elderly have already been controlled for in every regression. Nevertheless, to confirm that the main findings are not driven by omitting relevant variables, I control for healthcare capacity, measured by the number of hospitals and clinics per 1,000 individuals; and public resources, captured by a dummy variable that equals one if a municipality was located in the disaster relief act applied areas, and zero otherwise. The act was applied to the areas where the government defined to be damaged and these areas were targeted for providing various public support.

Panel A2 of Table 6 reports coefficient estimates for equation (1) with an additional control, the dummy variable for the areas targeted by the disaster relief act. The results are robust to the inclusion of the additional control. Panel A3 further controls for healthcare capacity. A limitation of including the measure of healthcare capacity is that sample size becomes smaller than the corresponding estimates in Table 4 due to missing values in the measure of healthcare capacity. Panel A3 indicates that the effect on the mortality of people in their 80s or older is not sensitive to the inclusion of the additional control. On the other hand, the effect on the mortality of individuals in their 70s is no longer statistically significant. To investigate whether the change in the result is

\footnotetext{
${ }^{18}$ Because levels of child and young adult mortality are low in my sample, some observations equal zero. Thus, the logged value is not defined. I therefore recode zero to one and take the log of the recoded values to make the coefficient estimates comparable to the previous results. Additionally, I also consider a different functional form specification of child and young adult mortality: raw values of mortality. The results are not sensitive to the specification of functional form.
} 
Table 6: Alternative regression specifications.

\begin{tabular}{|c|c|c|c|c|c|c|}
\hline \multirow[t]{3}{*}{ Dependent variable: } & \multirow{2}{*}{\multicolumn{2}{|c|}{ Volunteer }} & \multicolumn{4}{|c|}{ Mortality by age cohort } \\
\hline & & & \multicolumn{2}{|c|}{ Reduced-form } & \multicolumn{2}{|c|}{ IV } \\
\hline & Damage & Std. err. & Damage & Std. err. & Volunteer & Std. err. \\
\hline \multicolumn{7}{|c|}{ A. Additional controls } \\
\hline \multicolumn{7}{|c|}{ A1. Monetary donation } \\
\hline \# Deaths in 50s & $0.201 * * *$ & $(0.037)$ & -0.004 & $(0.013)$ & -0.021 & $(0.065)$ \\
\hline \# Deaths in $60 \mathrm{~s}$ & $0.207 * * *$ & $(0.038)$ & 0.001 & (0.009) & 0.006 & $(0.041)$ \\
\hline \# Deaths in $70 \mathrm{~s}$ & $0.204 * * *$ & $(0.039)$ & $-0.016 *$ & (0.009) & $-0.078 * *$ & $(0.037)$ \\
\hline \# Deaths in $80+$ & $0.214 * * *$ & $(0.040)$ & $-0.032 * * *$ & $(0.006)$ & $-0.150 * * *$ & $(0.042)$ \\
\hline \multicolumn{7}{|l|}{ A2. Public resources } \\
\hline \# Deaths in 50s & $0.170 * * *$ & $(0.040)$ & 0.002 & $(0.014)$ & 0.012 & $(0.080)$ \\
\hline \# Deaths in 60s & $0.177 * * *$ & $(0.042)$ & -0.001 & $(0.007)$ & -0.008 & $(0.042)$ \\
\hline \# Deaths in $70 \mathrm{~s}$ & $0.176 * * *$ & $(0.042)$ & $-0.013 *$ & $(0.007)$ & $-0.074 *$ & $(0.043)$ \\
\hline \# Deaths in $80+$ & $0.185 * * *$ & $(0.046)$ & $-0.031 * * *$ & $(0.006)$ & $-0.169 * * *$ & $(0.056)$ \\
\hline \multicolumn{7}{|c|}{ A3. Healthcare capacity } \\
\hline \# Deaths in $50 \mathrm{~s}$ & $0.181 * * *$ & $(0.063)$ & -0.010 & $(0.016)$ & -0.057 & $(0.096)$ \\
\hline \# Deaths in 60s & $0.182 * * *$ & $(0.063)$ & $-0.055 * * *$ & $(0.020)$ & $-0.302 *$ & $(0.167)$ \\
\hline \# Deaths in 70s & $0.182 * * *$ & $(0.063)$ & 0.003 & $(0.017)$ & 0.017 & $(0.095)$ \\
\hline \# Deaths in $80+$ & $0.182 * * *$ & $(0.064)$ & $-0.057 * * *$ & $(0.006)$ & $-0.313 * * *$ & $(0.113)$ \\
\hline \multicolumn{7}{|c|}{ B. Alternative dependent var. } \\
\hline \# Deaths in 00s & $0.207 * * *$ & $(0.040)$ & -0.013 & $(0.014)$ & -0.062 & $(0.063)$ \\
\hline \# Deaths in $10 \mathrm{~s}$ & $0.206^{* * *}$ & $(0.040)$ & 0.010 & $(0.012)$ & 0.050 & $(0.059)$ \\
\hline \# Deaths in $20 \mathrm{~s}$ & $0.206 * * *$ & $(0.039)$ & 0.005 & $(0.010)$ & 0.024 & $(0.047)$ \\
\hline \# Deaths in $30 \mathrm{~s}$ & $0.198 * * *$ & $(0.030)$ & -0.008 & $(0.016)$ & -0.039 & $(0.082)$ \\
\hline
\end{tabular}

Notes: $* p<.10, * * p<.05$, and $* * * p<.01$. Standard errors are clustered by municipality. First-stage and reduced-form estimates are the estimated coefficients on the damage indicator. The IV estimates are the estimates of $\beta_{1}$ in equation (1). Rows in each panel correspond to the regressions for the mortality of individuals in their 50s, 60s, 70s, and 80 or older, respectively, except Panel B (logged number of deaths of those in their 00s, 10s, 20s, and 30s). Refer to Table 3 for the controls included in Panel B. Panels A1 to A3 additionally control for logged donations of money to charity per capita; a dummy variable for the areas where the disaster relief act was applied; and the number of hospitals and clinics per 1,000 individuals, respectively. Due to missing values, the sample sizes in Panels A1 to A3 are 833, 838, and 707, respectively, except for the regression for individuals in their 50s $(820,825$, and 695 observations). The sample size in Panel B is 838 . 
caused by the omission of relevant variable or a change in sample size, equation (1) is estimated using the smaller sample without controlling for healthcare capacity. The estimated elasticity, 0.020, is not statistically different from Panel A3, implying that the change in the coefficient estimate is likely to be driven by a change in sample size.

I now investigate whether the results are driven by a difference in the pre-earthquake characteristics of volunteering. As Kobe had never been hit by major earthquakes prior to the earthquake in 1995, the earthquake shock would have been unanticipated. However, Hyogo Prefecture had been repeatedly hit by earthquakes prior to 1995 if not Kobe itself. Because areas affected by the earthquakes were spread across Hyogo Prefecture, it is unlikely that these earthquakes generated differential pre-earthquake trends in volunteering between the treatment and the control groups. Nevertheless, in order to empirically examine this possibility, earthquake damage is falsely assigned to the pre-earthquake period. Damage indicators are now included separately by year and equal positive values from 1991 to 2000 in the municipalities with positive levels of damage, and zero otherwise. The damage indicator in the year 1990 is omitted as the default year. Panel A of Table 7 reports the first-stage estimates of equation (1). The estimates indicate a lower level of volunteering in the treatment group prior to the earthquake, although the difference is not significantly different from zero. In contrast, there is a persistent and significant difference after the earthquake. The findings in the previous section are thus unlikely to be driven by a pre-earthquake difference in volunteering. An interesting point to note is that the level of volunteering sharply increased by approximately 10 to 20 percent after the earthquake and remained at nearly the same level, implying that the earthquake caused a persistent rather than a temporary change in volunteering.

In a similar vein, it might be the case that norms of cooperation are more developed in municipalities close to the fault that caused the Kobe earthquake because the damaged municipalities lie in an area with a risk of earthquakes. To examine this possibility, I omit the treatment group from my sample and falsely assign treatment status to municipalities lying just outside the original treatment group (false treatment group). The municipalities retained in the sample (i.e., the false treatment group and the control group) did not record any damage due to the earthquake and thus were presumably unaffected by the earthquake, while the false treatment group lies closer to the fault. Panel B of Table 7 presents the coefficient estimates for a false treatment dummy that equals one for municipalities in the false treatment group after the earthquake, and zero otherwise. The estimates show no statistically significant difference between the false treatment and control groups. Thus, the findings in the previous section are unlikely to be driven by a difference in volunteering according to geographical proximity to the fault. ${ }^{19}$

\footnotetext{
${ }^{19}$ There are two municipalities in the treatment group that reported one individual lightly injured and are geographically detached from the rest of municipalities. These two municipalities are included in the control group because the objective of this exercise is to examine whether the level of volunteering differs according to geographical proximity
} 
Table 7: Falsification exercises.

\begin{tabular}{|c|c|c|c|c|}
\hline & (1) & (2) & (3) & (4) \\
\hline Second-stage outcome: & \# Deaths 50s & \# Deaths 60s & \# Deaths 70s & \# Deaths 80+ \\
\hline Dependent variable: & Volunteer & Volunteer & Volunteer & Volunteer \\
\hline \multicolumn{5}{|c|}{ A. Pre- vs. post-earthquake } \\
\hline \% Damage 1991 & $\begin{array}{l}-0.053 \\
(0.058)\end{array}$ & $\begin{array}{l}-0.051 \\
(0.058)\end{array}$ & $\begin{array}{l}-0.051 \\
(0.057)\end{array}$ & $\begin{array}{l}-0.051 \\
(0.057)\end{array}$ \\
\hline \% Damage 1992 & $\begin{array}{l}-0.073 \\
(0.058)\end{array}$ & $\begin{array}{c}-0.072 \\
(0.057)\end{array}$ & $\begin{array}{l}-0.073 \\
(0.057)\end{array}$ & $\begin{array}{l}-0.072 \\
(0.057)\end{array}$ \\
\hline \% Damage 1993 & $\begin{array}{l}-0.048 \\
(0.044)\end{array}$ & $\begin{array}{l}-0.047 \\
(0.045)\end{array}$ & $\begin{array}{l}-0.047 \\
(0.045)\end{array}$ & $\begin{array}{l}-0.047 \\
(0.044)\end{array}$ \\
\hline \% Damage 1994 & $\begin{array}{l}-0.019 \\
(0.039)\end{array}$ & $\begin{array}{l}-0.010 \\
(0.039)\end{array}$ & $\begin{array}{l}-0.016 \\
(0.039)\end{array}$ & $\begin{array}{l}-0.002 \\
(0.044)\end{array}$ \\
\hline \% Damage 1996 & $\begin{array}{c}0.123 * * \\
(0.054)\end{array}$ & $\begin{array}{c}0.133 * * \\
(0.053)\end{array}$ & $\begin{array}{c}0.128 * * \\
(0.054)\end{array}$ & $\begin{array}{c}0.142 * * \\
(0.057)\end{array}$ \\
\hline \% Damage 1997 & $\begin{array}{c}0.174 * * * \\
(0.046)\end{array}$ & $\begin{array}{c}0.181 * * * \\
(0.046)\end{array}$ & $\begin{array}{c}0.175 * * * \\
(0.046)\end{array}$ & $\begin{array}{c}0.190 * * * \\
(0.051)\end{array}$ \\
\hline \% Damage 1998 & $\begin{array}{c}0.172 * * * \\
(0.044)\end{array}$ & $\begin{array}{c}0.179 * * * \\
(0.044)\end{array}$ & $\begin{array}{c}0.173 * * * \\
(0.044)\end{array}$ & $\begin{array}{c}0.188 * * * \\
(0.048)\end{array}$ \\
\hline \% Damage 1999 & $\begin{array}{c}0.161 * * * \\
(0.035)\end{array}$ & $\begin{array}{c}0.174 * * * \\
(0.033)\end{array}$ & $\begin{array}{c}0.170 * * * \\
(0.035)\end{array}$ & $\begin{array}{c}0.184 * * * \\
(0.038)\end{array}$ \\
\hline \% Damage 2000 & $\begin{array}{c}0.156^{* * * *} \\
(0.034)\end{array}$ & $\begin{array}{c}0.169 * * * \\
(0.034)\end{array}$ & $\begin{array}{c}0.165^{* * *} \\
(0.036)\end{array}$ & $\begin{array}{c}0.180 * * * \\
(0.038)\end{array}$ \\
\hline \multicolumn{5}{|c|}{ B. False treatment vs. control } \\
\hline False treatment & $\begin{array}{l}-0.105 \\
(0.154)\end{array}$ & $\begin{array}{l}-0.151 \\
(0.141)\end{array}$ & $\begin{array}{l}-0.098 \\
(0.137)\end{array}$ & $\begin{array}{r}-0.122 \\
(0.133)\end{array}$ \\
\hline
\end{tabular}

Notes: $* * p<.05$ and $* * * p<.01$. Standard errors are clustered by municipality. The dependent variable is the logged number of volunteers. Panel A falsely assigns a damage indicator to the pre-earthquake period, i.e., year $<1995$. The sampled municipalities are the treatment group and the control group (84 municipalities) except Panel B (the false treatment group and the control group, 58 municipalities). Refer to Table 3 for controls included in the analysis and sample sizes except Panel B (565 for the regression for individuals in their 50s, and 578 for the rest). 
Next, a series of robustness checks are conducted using different sample specifications. Recall that I omit severely damaged municipalities close to the epicenter from the sample to address the concern that the earthquake damage or earthquake-related disruptions had a long-term effect on mortality (cf. Figure 3). As the loss of life was concentrated in the four omitted municipalities, the long-term effect of the earthquake on mortality is likely to be addressed. One may be concerned, however, that the results are sensitive to sample specification. To address this concern, I present the results based on the full sample, and the samples without the one to five most severely damaged municipalities. The distribution of mortality due to the earthquake is highly negatively skewed, and the most severely damaged municipality, Kobe, alone accounts for 71 percent of the total number of deaths. Following Kobe, the top two to five most severely damaged municipalities account for 89 percent, 96 percent, 98 percent and 98 percent of the total number of deaths, respectively.

Table 8 presents a series of robustness checks using alternative definitions of severely damaged municipalities. The first-stage estimates reported in column (1) are robust to different sample specifications and consistently highly statistically significant. An interesting point to note is that the magnitudes of the coefficients tend to increase as more municipalities are omitted, implying that the level of volunteering increased most not in the most severely damaged but in moderately damaged municipalities. A possible interpretation is that individuals in the most severely damaged areas could not afford to volunteer because they themselves or their homes were heavily damaged. In contrast, individuals in the moderately damaged areas understood the importance of cooperation as they had been affected by the earthquake, but because they did not suffer heavy damage, they could afford to volunteer and help others. Consequently, the notion of volunteering may have developed more in the moderately damaged areas.

The IV estimates presented in column (2) also reconfirm the previous findings that volunteering had no statistically significant effect on the mortality of individuals in their 50s and 60s, while it significantly reduced the mortality of people in their 70s and 80s or older. An interesting point to note is that, although the IV estimates from alternative sample specifications decrease (in absolute terms) as more municipalities are omitted, the estimates are not significantly different from each other, implying that the earthquake is unlikely to have disproportionately killed vulnerable individuals within each age band. This is not surprising, as the vast majority of victims were crushed or choked to death due to the collapse of their homes and passed away within 24 hours after the earthquake occurred (Hyogo Prefecture, 2005b). ${ }^{20}$ Therefore the initial health endowments of victims within each age band may have not been particularly important for survival, unlike deaths due to, for example, hunger, for which people with greater initial health endowments are more

to the fault. Treating the two municipalities as the treatment group and omitting them from the sample yields similar results.

${ }^{20}$ The earthquake occurred at 5:46 in the morning, and most victims died at home. 
Table 8: Alternative sample specifications.

\begin{tabular}{|c|c|c|c|c|}
\hline & \multicolumn{2}{|c|}{ First-stage } & \multicolumn{2}{|c|}{ IV } \\
\hline & \multicolumn{2}{|c|}{ (1) } & \multicolumn{2}{|c|}{ (2) } \\
\hline A1. \# Deaths in 50s & $0.163 * * *$ & $(0.034)$ & -0.060 & $(0.087)$ \\
\hline A2. \# Deaths in $60 \mathrm{~s}$ & $0.170 * * *$ & $(0.035)$ & -0.050 & $(0.067)$ \\
\hline A3. \# Deaths in 70 s & $0.168 * * *$ & $(0.036)$ & $-0.114 *$ & $(0.061)$ \\
\hline A4. \# Deaths in $80+$ & $0.178 * * *$ & $(0.037)$ & $-0.162 * * *$ & $(0.047)$ \\
\hline \multicolumn{5}{|c|}{ B. 1 omitted municipality } \\
\hline B1. \# Deaths in 50s & $0.162 * * *$ & $(0.034)$ & -0.058 & $(0.087)$ \\
\hline B2. \# Deaths in $60 \mathrm{~s}$ & $0.170 * * *$ & $(0.034)$ & -0.049 & $(0.067)$ \\
\hline B3. \# Deaths in 70 s & $0.167 * * *$ & $(0.036)$ & $-0.114 *$ & $(0.062)$ \\
\hline B4. \# Deaths in $80+$ & $0.178 * * *$ & $(0.037)$ & $-0.163 * * *$ & $(0.047)$ \\
\hline \multicolumn{5}{|c|}{ C. 2 omitted municipalities } \\
\hline C1. \# Deaths in 50s & $0.161 * * *$ & $(0.034)$ & -0.055 & $(0.087)$ \\
\hline C2. \# Deaths in $60 \mathrm{~s}$ & $0.169 * * *$ & $(0.035)$ & -0.049 & $(0.068)$ \\
\hline C3. \# Deaths in 70s & $0.167 * * *$ & $(0.036)$ & $-0.115^{*}$ & $(0.063)$ \\
\hline C4. \# Deaths in $80+$ & $0.177 * * *$ & $(0.037)$ & $-0.162 * * *$ & $(0.048)$ \\
\hline \multicolumn{5}{|c|}{ D. 3 omitted municipalities } \\
\hline D1. \# Deaths in 50s & $0.187 * * *$ & $(0.034)$ & -0.028 & $(0.075)$ \\
\hline D2. \# Deaths in 60s & $0.195 * * *$ & $(0.035)$ & -0.006 & $(0.042)$ \\
\hline D3. \# Deaths in $70 \mathrm{~s}$ & $0.192 * * *$ & $(0.036)$ & $-0.088 * *$ & $(0.040)$ \\
\hline D4. \# Deaths in $80+$ & $0.202 * * *$ & $(0.037)$ & $-0.154 * * *$ & $(0.044)$ \\
\hline \multicolumn{5}{|c|}{ E. 4 omitted municipalities } \\
\hline E1. \# Deaths in 50s & $0.196 * * *$ & $(0.037)$ & -0.027 & $(0.071)$ \\
\hline E2. \# Deaths in $60 \mathrm{~s}$ & $0.204 * * *$ & $(0.038)$ & -0.005 & $(0.040)$ \\
\hline E3. \# Deaths in 70 s & $0.200 * * *$ & $(0.039)$ & $-0.085 * *$ & $(0.038)$ \\
\hline E4. \# Deaths in $80+$ & $0.211 * * *$ & $(0.040)$ & $-0.152 * * *$ & $(0.042)$ \\
\hline \multicolumn{5}{|c|}{ F. 5 omitted municipalities } \\
\hline F1. \# Deaths in 50s & $0.199 * * *$ & $(0.040)$ & -0.028 & $(0.069)$ \\
\hline F2. \# Deaths in $60 \mathrm{~s}$ & $0.206 * * *$ & $(0.041)$ & -0.009 & $(0.038)$ \\
\hline F3. \# Deaths in 70s & $0.203 * * *$ & $(0.042)$ & $-0.083 * *$ & $(0.037)$ \\
\hline F4. \# Deaths in $80+$ & $0.214 * * *$ & $(0.044)$ & $-0.148 * * *$ & $(0.043)$ \\
\hline
\end{tabular}

Notes: $* p<.10, * * p<.05$, and $* * * p<.01$. Standard errors are clustered by municipality. First-stage estimates are the estimated coefficients on the damage indicator. The IV estimates are the estimates of $\beta_{1}$ in equation (??). Refer to Table 3 for controls included in the analysis. Each panel corresponds to a different sample specification: panels A to F use the control group (56 municipalities) and the treatment group, where zero to five of the most severely damaged municipalities, respectively, are omitted from the sample. Rows 1 to 4 in each panel correspond to the regressions for the mortality of individuals in their 50s, 60s 70s and 80s or older, respectively. 
likely to survive.

Finally, one may be concerned that the results in the previous section are a product of coincidence due to the use of a particular damage indicator, the percentage of individuals injured, as an instrument. I now investigate whether the results are robust to different choices of damage indicators. Table 9 reports the results where volunteering is instrumented with four different damage indicators: percentage of (i) individuals seriously injured, (ii) individuals lightly injured, (iii) households whose homes were completely destroyed and (iv) households whose homes were half destroyed. Column (1) indicates that earthquake damage significantly raised the level of volunteering regardless of the damage indicator used, which in turn significantly reduced the mortality of individuals in their 70s and 80s or older (column (2)). Thus, the results in the previous section are not sensitive to the choice of instruments.

\section{Conclusions}

This paper explored the causal effect of volunteer work providing daily assistance to the elderly on elderly mortality. To identify the causal effect on mortality, I exploit exogenous variation in volunteering caused by the Kobe earthquake that hit midwestern Japan in 1995. The level of volunteering sharply increased in municipalities hit by the earthquake, while other municipalities not hit by the earthquake did not experience such a sharp increase in volunteering. Based on a comparison of mortality between the municipalities with no or little loss of life due to the earthquake that experienced the sharp increase in the level of volunteering, and the nearby municipalities that were not hit by the earthquake, I find that volunteering significantly reduced the mortality of people in their 70 s and 80 s or older. The effect on the mortality of people in their 80 s or older is roughly double its effect on those in their 70s. Evaluated at the mean, the life of approximately one person aged 80 or older (out of 125 persons) was saved in a given year when the number of volunteers increased by 100 (out of 1,389 persons). Conditional on living until 80 or older, a one-year extension of life is a substantial increase, corresponding to an approximately 11 percent increase in life expectancy.

Although the nature of the data does not allow me to determine if the reduction in mortality occurred among volunteers or care receivers, that of people in their 80s or older is likely to be driven by care recipients because every volunteer is younger than 80 . My estimates capture a contemporaneous effect of volunteering on mortality; thus, they reflect a short- to mid-term effect of volunteering. To the extent that volunteering also reduces mortality of care recipients and/or volunteers in the future, the effect of volunteering on mortality may be even higher in the long run. In addition, it is worth noting that my estimation captures the effect of volunteer work on one of a number of possible outcomes. There could also be other effects of volunteer work such 
Table 9: Alternative instruments.

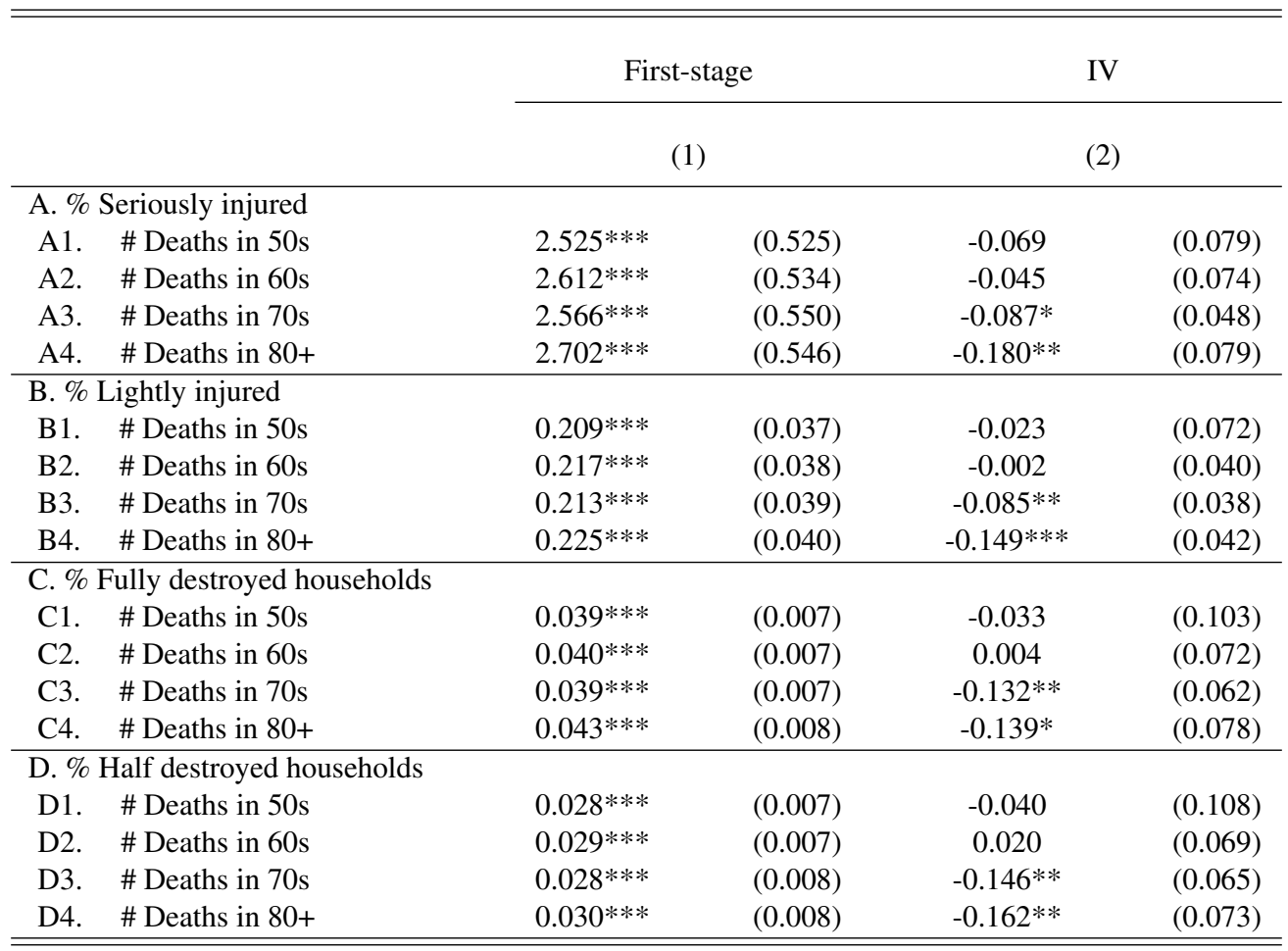

Notes: $* p<.10, * * p<.05$, and $* * * p<.01$. Standard errors are clustered by municipality. First-stage estimates are the estimated coefficients on the damage indicator, where the percentage of individuals injured is used as an indicator except Panel A (percentage of individuals seriously injured, lightly injured, and households who had their homes completely destroyed or half destroyed). The IV estimates are the estimates of $\beta_{1}$ in equation (??). Rows 1 to 4 in each panel correspond to the regressions for the mortality of individuals in their 50s, 60s 70s and 80s or older, respectively. Refer to Table 3 for controls included in the analysis and the sample size in Panel A. Panel B additionally controls for the number of hospitals and clinics per 1,000 individuals. Due to missing values, the sample size in Panel B is 707, except for the regression for individuals in their 50s (695 observations). 
as improving morbidity of the elderly and enhancing the utility of volunteers, making its effects even larger.

Broadly, my results have various important policy implications. For instance, by encouraging volunteer work for the elderly, a government may be able to curb public healthcare expenditures without compromising health support for the elderly. This could be an important policy measure amid the ongoing population aging and resulting increase in healthcare expenditures across the world. Similarly, in countries with limited provision of public healthcare services (e.g., the United States), a government, by supporting volunteer activity for the elderly, may still be able to improve the health of the elderly who cannot afford private healthcare. In fact, volunteer work is encouraged by governments in many countries. For instance, the UK government has been promoting "a culture of generosity", whereby the public is encouraged to volunteer time and money to help improve life for all. It spent $£ 13.9$ billion on voluntary organizations in $2009 / 10$, corresponding to approximately two percent of total spending (Clarke et al., 2012). Over the past decade, government spending on the voluntary sector has grown by 61 percent in real terms, showing a growing importance of the voluntary sector in providing public services. Given the wide variety of volunteer work being conducted, it appears crucial for more studies to shed further light on other potential outcomes of volunteering in the future. 


\section{Data Appendix}

\section{Computation of Some Covariates}

Data on the number of unemployed and those in the labor force are available in census years, 1990, 1995 and 2000. To compute the annual unemployment rate, I linearly interpolate the number of unemployed and those in the labor force between census years. For age-cohort-specific population, prefecture level data are available in each year, but municipality level data are available only in census years. Therefore, prefecture level data in non-census years are decomposed into the municipality level, using municipality level population in the nearest census year as a weight.

\section{Life Expectancy}

Life expectancy at age 80 is computed based on the methodology used by Jayachandran and Lleras-Muney (2009). Consider an individual who has survived until age 80 . Data on the mortality rate are available at a five-year age band, and the mortality rate is assumed to be constant at each age in the five-year band. Using one year as the age increment to be iterated over, the formula for life expectancy at age 80 is:

$$
e(80)=\left\{\sum_{t=80}^{110}\left(t+\frac{1}{2}\right) \times_{t} P_{80} \times q_{t}\right\}-80
$$

, where ${ }_{t} P_{80}$ is the probability of surviving from age 80 to age $t$, and $q_{t}$ is the probability of dying at age $t$ (the mortality rate for age $t$ ). The end of life is assumed to be the maximum of age 110 . In the first term, the age at each subsequent year after 80 is multiplied by the probability of surviving each subsequent year, given the mortality rate $q_{t}$. The factor of $1 / 2$ is required because death is assumed to occur at the midpoint of the discrete one-year period. The summation accumulates the expected years of life at successive ages. As the measure is of years of life remaining at age 80 conditional on surviving until that age, 80 is subtracted from the first term. Because the original data are mortality rates, ${ }_{t} P_{80}$ is itself constructed as follows:

$$
{ }_{t} P_{80}=\prod_{\phi=80}^{t-1}\left(1-q_{\phi}\right) .
$$




\section{Intensity and Cost of Volunteering}

Table A.1 summarizes the computation of total annual hours worked per volunteer and the cost of volunteer labor. The computation presented in Table A.1 must be interpreted with the following caveats. Firstly, the computation of the total hours worked per volunteer uses the assumptions on volunteer hours involved per activity. Due to data limitations, the assumptions on the volunteer hours involved per activity are made based on data on the contents of volunteer activity. Thus, the estimates presented in Table A.1 should be interpreted as an approximation rather than the accurate measure of the intensity of volunteer work. Secondly, the estimate of the cost of volunteer labor consists only of the opportunity cost. To the extent that volunteer work involves organization costs such as the costs of scheduling and matching volunteers and care recipients, the cost of volunteer labor estimate is likely to be understated. Despite these limitations, I present annual hours worked per volunteer to provide a rough notion of volunteer hours required to reduce elderly mortality and the related opportunity cost.

Column (1) of Panel A presents the frequency of volunteer activity: 1,299 volunteer groups, corresponding to 33.7 percent of the total number of groups, engage in volunteer work at least once a week. As there are 29 volunteers per group on average, column (1) is multiplied by 29 to obtain the estimated number of volunteers (column (2)). One of the main volunteer activities is to organize community gatherings. Volunteers organize Bon dance festivals, bazaars, concerts and rice cake making festivals, etc. that are typically one-day events taking place once or twice a year. ${ }^{21}$ The other main activitiy of volunteers is to provide support for daily activities such as the delivery of meals, visits to homes, hospitals and care homes for a chat, and assistance with daily tasks including housework, going out, and bathing. Given the contents of the volunteer services, the assumptions regarding the intensity of volunteer activities are made as follows.

Volunteer groups that operate

- at least once a month engage in activities related to daily activities that involve one to three hours; and

- less than once a month engage in activities related to the organization of community gatherings that involve seven to nine hours

per volunteer per activity.

Column (3) summarizes these assumptions and column (4) aggregates this volunteer hours per activity to an annual level. For example, the second row of column (4) is obtained by 1 hour $\times$

\footnotetext{
${ }^{21}$ The Bon dance festival and the rice cake making festival are traditional Japanese festivals held in summer and winter, respectively.
} 
Table A.1

Intensity and cost of volunteering.

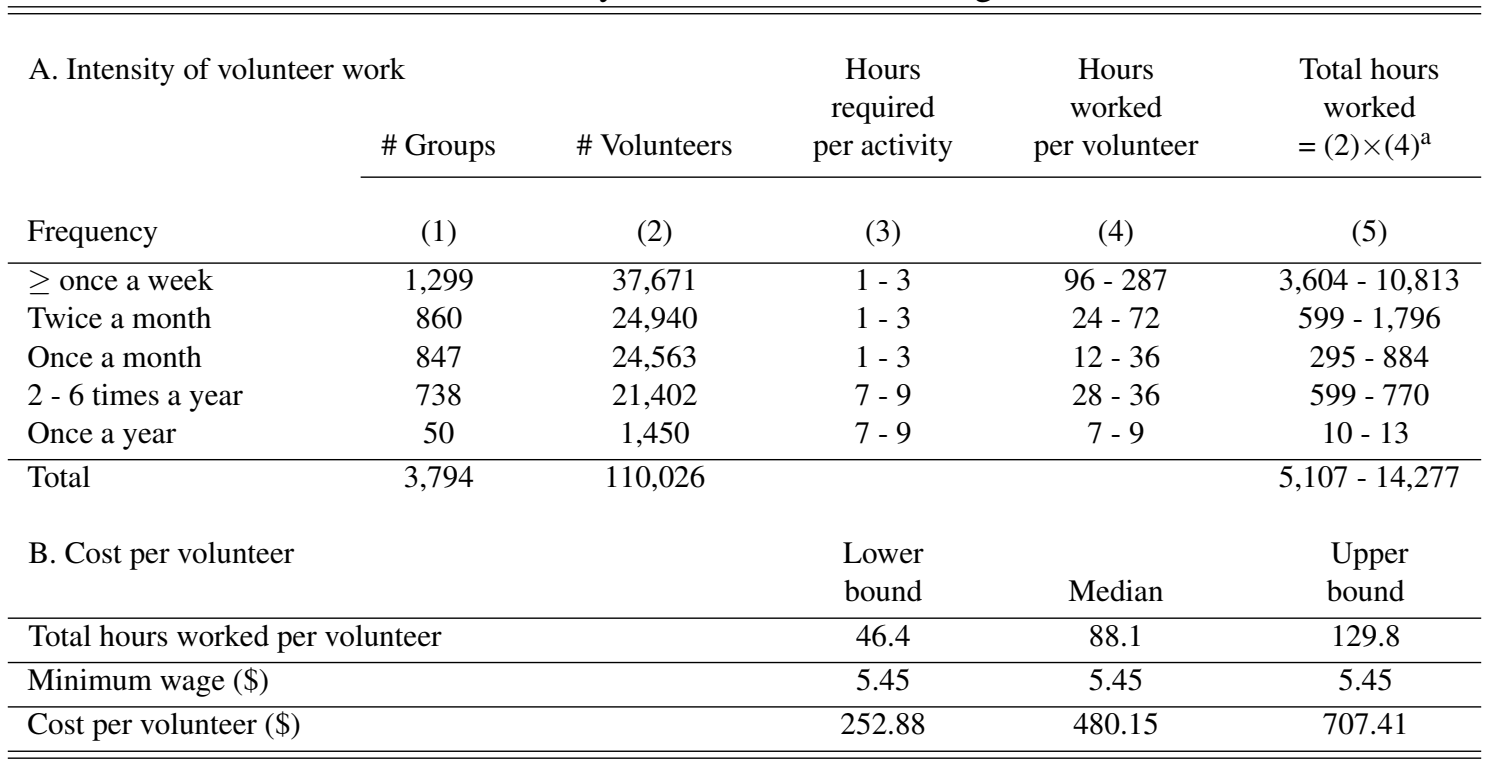

Notes: Hours worked are annual values. Minimum wage and the cost are in 1997 values. ${ }^{a}$ Expressed as 1,000 hours.

24 times $=24$ hours $\left(\right.$ lower bound) and 3 hours $\times 24$ times $=72$ hours $\left(\right.$ upper bound) ${ }^{22}$ Column (5) presents the total annual hours worked by volunteers. Finally, dividing the total annual hours worked by volunteers $(5,107,000$ - 14,277,000 hours) by the total number of volunteers, 110,026, yields the average annual hours worked per volunteer (46.4 - 129.8 hours, Panel B). Evaluated at the minimum wage in Hyogo Prefecture as of 1997, 46.4 to 129.8 hours of labor cost $\$ 252.88$ to $\$ 707.41$ with the median cost of $\$ 480.15$.

\footnotetext{
${ }^{22}$ For those who engage in volunteer work at least once a week (the first row, Panel A) and two to six times a year (the fourth row, Panel A) are assumed to work 1.84 times a week (i.e., 96 times a year) and four times a year, respectively. The average weekly number of volunteer activities for those who engage in volunteer work at least once a week, 1.84 times, is obtained from the Report on the Trend in Volunteer Activity in Hyogo Prefecture (Hyogo Council of Social Welfare, 1993) because the corresponding figure is not available in the 1997 report.
} 


\section{References}

Andreoni, J. (1989). Giving with impure altruism: applications to charity and Ricardian equivalence. Journal of Political Economy 97(6), 1447-1458.

Andreoni, J. (1990). Impure altruism and donations to public goods: a theory of warm-glow giving. The Economic Journal 100(401), 464-477.

Benabou, R. and J. Tirole (2006, December). Incentives and prosocial behavior. American Economic Review 96(5), 1652-1678.

Clarke, J., D. Kane, K. Wilding, and P. Bass (2012, March). The UK civil society almanac 2012. Technical Report 11, The National Council for Voluntary Organisations, London.

Day, K. M. and R. A. Devlin (1998). The payoff to work without pay: volunteer work as an investment in human capital. The Canadian Journal of Economics / Revue canadienne d'Economique 31(5), 1179-1191.

DellaVigna, S., J. A. List, and U. Malmendier (2012). Testing for atruism and social pressure in charitable giving. The Quarterly Journal of Economics 127(1), 1-56.

Duncan, B. (1999). Modeling charitable contributions of time and money. Journal of Public Economics 72(2), $213-242$.

Edgington, D. W. (2010). Reconstructing Kobe: The geography of crisis and opportunity. Vancouver: University of British Columbia Press.

Fire and Disaster Management Agency (2006, May). Final report on the great Hanshin-Awaji earthquake. Accessed: December 12007.

Fire Service and Disaster Prevention Devision (1996). The great Hanshin-Awaji earthquake record of Hyogo Prefecture over a year. Kobe: Hyogo Prefecture.

Fong, C. M. and E. F. P. Luttmer (2009, April). What determines giving to hurricane Katrina victims? experimental evidence on racial group loyalty. American Economic Journal: Applied Economics 1(2), 64-87.

Freeman, R. B. (1997, January). Working for nothing: the supply of volunteer labor. Journal of Labor Economics 15(1), 140-66.

Grossman, Z. (2010). Self-signaling versus social-signaling in giving. University of California at Santa Barbara, Economics working paper series, Department of Economics, UC Santa Barbara. 
Harris, A. H. S. and C. E. Thoresen (2005). Volunteering is associated with delayed mortality in older people: analysis of the longitudinal study of aging. Journal of Health Psychology 10(6), 739-752.

Health and Social Statistics Division (1990-2000). Report on the current population survey. Technical report, Ministry of Health, Labor and Welfare, Tokyo.

House, J. S., K. R. Landis, and D. Umberson (1988). Social relationships and health. Science 241(4865), 540-545.

Hyogo Council of Social Welfare (1991-2001, March). The Hyogo Council of Social Welfare activity report. Technical report, Hyogo Council of Social Welfare, Kobe.

Hyogo Council of Social Welfare (1993, March). Report on the trend in volunteer activity in Hyogo Prefecture. Technical report, Hyogo Council of Social Welfare, Kobe.

Hyogo Council of Social Welfare (1997, March). Report on the trend in volunteer activity. Technical report, Hyogo Council of Social Welfare, Kobe.

Hyogo Labor Bureau (1997, March). Revision of the minimum wage. Accessed: June 12013.

Hyogo Prefecture (1991-2001). National health insurance and the health insurance for the elderly in Hyogo. Technical report, Department of Health and Welfare.

Hyogo Prefecture (2005a). The great Hanshi-Awaji earthquake damage. Kobe.

Hyogo Prefecture (2005b, January). Survey on the death toll from the great Hanshin-Awaji earthquake. Accessed: May 12013.

Japanese Red Cross (1990-2000). The record of the Japanese Red Cross funds. Kobe.

Jayachandran, S. and A. Lleras-Muney (2009). Life expectancy and human capital investments: evidence from maternal mortality declines. The Quarterly Journal of Economics 124(1), 349397.

Kiecolt-Glaser, J. K. and R. Glaser (1995). Psychoneuroimmunology and health consequences: data and shared mechanisms. Psychosomatic Medicine 57(3), 269-274.

Landry, C. E., A. Lange, J. A. List, M. K. Price, and N. G. Rupp (2006). Toward an understanding of the economics of charity: evidence from a field experiment. The Quarterly Journal of Economics 121(2), 747-782. 
List, J. A. and D. Lucking-Reiley (2002, February). The effects of seed money and refunds on charitable giving: experimental evidence from a university capital campaign. Journal of Political Economy 110(1), 215-233.

Luoh, M.-C. and A. R. Herzog (2002). Individual consequences of volunteer and paid work in old age: health and mortality. Journal of Health and Social Behavior 43(4), 490-509.

Menchik, P. L. and B. A. Weisbrod (1987). Volunteer labor supply. Journal of Public Economics 32(2), $159-183$.

Morrow-Howell, N., J. Hinterlong, P. A. Rozario, and F. Tang (2003). Effects of volunteering on the well-being of older adults. The Journals of Gerontology Series B: Psychological Sciences and Social Sciences 58(3), 137-145.

Musick, M. A., A. R. Herzog, and J. S. House (1999). Volunteering and mortality among older adults: findings from a national sample. The Journals of Gerontology Series B: Psychological Sciences and Social Sciences 54B(3), 173-180.

Musick, M. A. and J. Wilson (2003). Volunteering and depression: the role of psychological and social resources in different age groups. Social Science \& Medicine 56(2), 259-269.

Oman, D., C. E. Thoresen, and K. Mcmahon (1999). Volunteerism and mortality among the community-dwelling elderly. Journal of Health Psychology 4(3), 301-316.

Piliavin, J. A. and E. Siegl (2007). Health benefits of volunteering in the Wisconsin longitudinal study. Journal of Health and Social Behavior 48(4), 450-464.

Shang, J. and R. Croson (2009). A field experiment in charitable contribution: the impact of social information on the voluntary provision of public goods. The Economic Journal 119(540), $1422-1439$.

Shmotkin, D., T. Blumstein, and B. Modan (2003). Beyond keeping active: concomitants of being a volunteer in old-old age. Psychology and Aging 18(3), 602 - 607.

Statistics Bureau (1990-2000). System of social and demographic statistics of Japan. Technical report, Ministry of Internal Affairs and Communications, Tokyo.

Stock, J. H., J. H. Wright, and M. Yogo (2002). A survey of weak instruments and weak identification in generalized method of moments. Journal of Business \& Economic Statistics 20(4), $518-29$.

Thoits, P. A. and L. N. Hewitt (2001). Volunteer work and well-being. Journal of Health and Social Behavior 42(2), 115-131. 
United Nations Center for Regional Development (1995). A call to arms: Report of the 17 January 1995 great Hanshin earthquake. UNCRD discussion paper, UNCRD, Nagoya.

Van Willigen, M. (2000). Differential benefits of volunteering across the life course. 55(5), $308-318$.

Vesterlund, L. (2003). The informational value of sequential fundraising. Journal of Public Economics 87(3-4), $627-657$.

Young, F. W. and N. Glasgow (1998). Voluntary social participation and health. Research on Aging 20(3), 339-362. 